
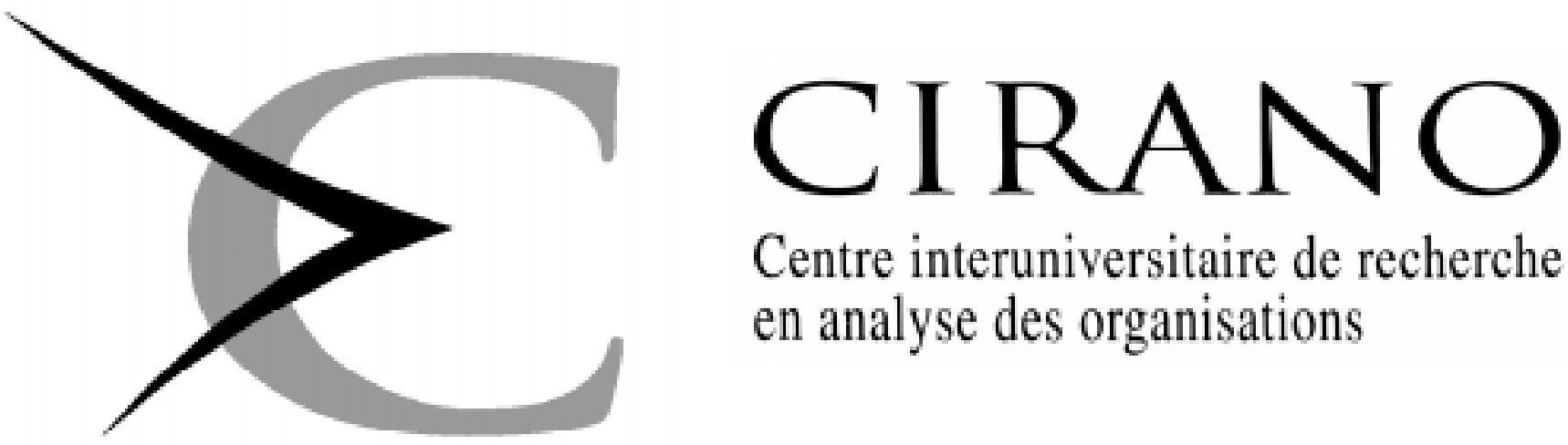

Centre interuniversitaire de recherche en analyse des organisations

Série Scientifique

Scientific Series

98s-08

\title{
Job Characteristics and the Form of Compensation
}

W. Bentley MacLeod, Daniel Parent 


\section{CIRANO}

Le CIRANO est une corporation privée à but non lucratif constituée en vertu de la Loi des compagnies du Québec. Le financement de son infrastructure et de ses activités de recherche provient des cotisations de ses organisations-membres, d'une subvention d'infrastructure du ministère de l'Industrie, du Commerce, de la Science et de la Technologie, de même que des subventions et mandats obtenus par ses équipes de recherche. La Série Scientifique est la réalisation d'une des missions que s'est données le CIRANO, soit de développer l'analyse scientifique des organisations et des comportements stratégiques.

CIRANO is a private non-profit organization incorporated under the Québec Companies Act. Its infrastructure and research activities are funded through fees paid by member organizations, an infrastructure grant from the Ministère de l'Industrie, du Commerce, de la Science et de la Technologie, and grants and research mandates obtained by its research teams. The Scientific Series fulfils one of the missions of CIRANO: to develop the scientific analysis of organizations and strategic behaviour.

\section{Les organisations-partenaires / The Partner Organizations}

-École des Hautes Études Commerciales

-École Polytechnique

-McGill University

- Université de Montréal

-Université du Québec à Montréal

-Université Laval

-MEQ

- MICST

-Avenor

- Banque Nationale du Canada

-Bell Québec

- Caisse de dépôt et placement du Québec

- Fédération des caisses populaires Desjardins de Montréal et de l'Ouest-du-Québec

-Hydro-Québec

- Industrie Canada

- Microcell Labs inc.

- Raymond, Chabot, Martin, Paré

- Scetauroute

- Société d'électrolyse et de chimie Alcan Ltée

-Téléglobe Canada

-Ville de Montréal

Ce document est publié dans l'intention de rendre accessibles les résultats préliminaires de la recherche effectuée au CIRANO, afin de susciter des échanges et des suggestions. Les idées et les opinions émises sont sous l'unique responsabilité des auteurs, et ne représentent pas nécessairement les positions du CIRANO ou de ses partenaires.

This paper presents preliminary research carried out at CIRANO and aims to encourage discussion and comment. The observations and viewpoints expressed are the sole responsibility of the authors. They do not necessarily represent positions of CIRANO or its partners.

ISSN 1198-8177 


\title{
Job Characteristics and the Form of Compensation"
}

\author{
W. Bentley MacLeod ${ }^{\dagger}$, Daniel Parent ${ }^{\ddagger}$
}

\section{Résumé / Abstract}

\begin{abstract}
Cet article cherche à organiser de façon systématique le choix des différentes méthodes de rémunération selon les caractéristiques observables des emplois. Par après, nous examinons de façon empirique les facteurs influençant le choix de ces méthodes en utilisant l'information concernant les caractéristiques des emplois contenue dans le Quality of Employment Survey, le National Longitudinal Survey of Youth, le Panel Study of Income Dynamics et le Current Population Survey. La principale conclusion est qu'il n'existe aucun modèle de la relation d'emploi qui puisse expliquer de façon satisfaisante la variation observée dans les méthodes de compensation.Les résultats plus spécifiques sont les suivants : a) le nombre de tâches semble être associé à l'emploi de contrats incomplets; b) la rémunération à la pièce va de paire avec la parcimonie des tâches de même qu'avec l'autonomie accrue du travailleur; c) un marché du travail local « serré » tend à être associé avec l'utilisation de bonis et de promotions plutôt que des salaires d'efficience.

In this paper we introduce a way to systematically organize the choice between different forms of compensation based upon observable job characteristics. Secondly, we explore the determinants of compensation based upon questionnaire responses concerning job characteristics and methods of pay contained in the Quality of Employment Survey (QES), the National Longitudinal Survey of Youth (NLSY), the Panel Study of Income Dynamics (PSID), and the Current Population Survey. The main conclusion is that there is no single model of the employment relationship that can explain the variation in compensation form. We draw upon both agency and incomplete contract models to study the interplay between job characteristics and compensation. Specific results include a) the number of tasks seems to be associated with the use of incomplete contracts; b) Piece rate jobs tend to be associated with more worker autonomy and fewer tasks performed than hourly paid jobs; c) tight labor market conditions tend to be associated with the use of bonuses and promotions instead of efficiency wages.
\end{abstract}

\footnotetext{
* Corresponding Author: Daniel Parent, CIRANO, 2020 University Street, 25th floor, Montréal, Qc, Canada H3A 2A5 Tel: (514) 985-4027 Fax: (514) 985-4000 e-mail: parentd@ cirano.umontreal.ca Special thanks to David Card, Janet Currie, and Hank Farber for helpful comments and suggestions. We also thank participants at Berkeley, UCLA, USC, the Princeton Labor Lunch, and the Chicago 1998 Econometric Society meetings. Bentley MacLeod's research is supported by National Science Foundation, Grant SBR-9709333, while Daniel Parent's research is supported by Québec's FCAR.

${ }^{\dagger}$ University of Southern California

\# Université de Sherbrooke, CRDE and CIRANO
} 
Mots Clés : $\quad$ Caractéristiques des emplois, méthodes de rémunération, contrats incomplets, modèles d'agence

Keywords : $\quad$ Job characteristics, methods of pay, incomplete contracts, agency models 


\section{Introduction}

Employers use a variety of compensation systems to motivate workers, including piece rates, bonus pay, profit sharing, promotion and delayed compensation. In addition to these explicit reward mechanisms, fixed hourly or weekly wages usually require the worker to perform his or her duties satisfactorily or face dismissal. The purpose of this paper is to provide an overview of the different forms of compensation observed in the US, and to explore some explanations for this variation based upon the interplay between job characteristics and the incidence of a particular form of compensation. Data concerning job characteristics and methods of pay is based upon questionnaire responses in the Quality of Employment Survey (QES) and the National Longitudinal Survey of Youth (NLSY). We also use the Panel Study of Income Dynamics (PSID) and the Current Population Survey (CPS) by merging these files with the average characteristics by occupation categories computed with the QES data.

Given the complexity and variety of compensation systems, there is no single theoretical model that can explain all the variation in the data. Rather, our estimation strategy is based upon combining the insights from a number of theoretical models. Drawing upon both agency theory (Ross (1973) and Holmstrom (1979)) and the literature based upon the incomplete contract model (Grossman and Hart (1986), Bull (1987) and MacLeod and Malcomson (1989)) we model observed compensation as a hierarchial choice process that permits us to estimate the impact of job characteristics upon incidence of a particular contract form using a sequence of binary choice models. Using this approach we find that many of the predictions of the models are consistent with our results over the four data sets.

We find that the some job characteristics affect the likelihood of piece rate contracts differently from bonus pay or commission contracts. This suggests that these forms of compensation may have different economic roles, and are not simply different names for a similar underlying pay for performance relationship. In particular more complex jobs are associated with incomplete compensation contracts and less use of piece rates, a result that is consistent with the earlier work of Brown (1990). This interpretation finds further support with the finding that increases in the local unemployment rate decreases the likelihood that a firm uses bonus pay, a prediction of the incomplete contracts model (MacLeod and Malcomson (1997)).

There is a large literature that explores the impact of compensation on worker selection and behavior. For example Pencavel (1977), Seiler 
(1984) and Brown (1990) find that piece rate jobs tend to pay higher wages. Bishop $(1987,1990)$ shows that wage levels and the threat of dismissal have a positive effect on worker productivity. Finally, the large literature on executive compensation, including Antle and Smith (1986), Jensen and Murphy (1990), Gibbons and Murphy (1992) and many others, find that there is a strong relationship between pay and performance. In this paper we begin the task of taking a broader view of the different possible forms of compensation, and ask how we can discriminate between the different determinants of pay that have been discussed in the literature.

In section 2 we begin with a description of the data sets. We begin with the Quality of Employment Survey (QES) (1973-1977 panel), that contains worker responses concerning both job characteristics and the form of compensation. There we find a great deal of variation in both compensation forms and job characteristics. To check upon the robustness of the results we also use the National Longitudinal Survey of Youth (NLSY), the Panel Study of Income Dynamics (PSID) and the January 1977 Current Population Survey (CPS). Both the QES and NLSY data sets contain questions about the work environment and the form of compensation. In the case of the QES, the 1977 survey has questions about both the form of the contract and job characteristics while in the case of the NLSY, the job attribute questions are asked in different years from the pay method questions.

To circumvent this latter difficulty, we calculate group averages (20 occupation categories) of the job characteristics and merge these group averages to the corresponding cells in the years where we do have questions about pay methods. In the case of the PSID and the CPS, we use a similar merger-by-cell procedure using the group averages computed with the QES data. Given the group-level nature of these variables, we are careful to take that into account in the estimation procedures.

In section 3 of the paper we use the theory to help us organize the analysis of the data. One of the difficulties with the contract literature is that there is no accepted model of contract formation that is appropriate for all situations. Rather each model tends to highlight a different set of factors that are important for the determination of compensation. We deal with this problem by organizing the models into what we call a compensation hierarchy. This structure is used to organize our regressions into a series of qualitative choice models that can help us identify the impact of different job characteristics for each of the compensation trade-offs we consider.

Job characteristics are themselves partially endogenous. Our implicit identification hypothesis is that job characteristics, like capital is fixed 
in the short run, while compensation policies are flexible. Hence all compensation policies are chosen condition upon job characteristics. Several factors are likely to affect a job characteristic, but as in Holmstrom and Milgrom(1994), the theory predicts that observed variations in job characteristics result in observable variations in compensation policy. It is this effect that we attempt to identify in this paper.

In section 4 we discuss our estimation strategy in detail. Given that selection and incentive effects are also important for compensation form, we use a series of techniques to control for unobserved heterogeneity. The longitudinal nature of the data permits us to control for individual characteristics, and we also control for industry, tenure, experience, and the size of the firm. We find that the reported job characteristics have significant effects on at least one of the pairs of contractual choice. In addition to finding that job characteristics have an impact upon the trade-off between an explicit pay for performance system and fixed wages, we also find that non-contractible reward systems such are bonuses affect a significant number of workers. Moreover we find that the probability of using a bonus is positively related to a decrease in the local unemployment rate, a result that is consistent with the incomplete contract model.

Although we control for unobserved individual heterogeneity, "withinindividual" methods do not control for occupational matching. Therefore, to allow for the possibility that people who belong to the same group or occupation category self-select into a certain occupation because of comparative economic or taste advantages, we apply a semi-parametric selection correction technique recently proposed in the literature on the return to education Dahl (1997)). Although there is evidence of selection, we find that correcting for self-selection does not substantially affect our basic results in terms of the impact of the job attributes on the incidence of pay methods.

Furthermore, we also show that the results are robust to occupational classification errors by either directly applying the technique developed in (Krueger and Summers (1988)) for models estimated in first differences or by adapting it to the estimation in levels. Finally, a Hausman test is used to see if the binary choices are indeed independent. It is found that we cannot reject the hypothesis that the sequence of binary choices outlined in the theory is in fact appropriate. The final section concludes with a summary of the results, and discussion of some of the implications of the analysis. 


\section{The Data}

\subsection{The Quality of Employment Survey, 1973-1977.}

The Quality of Employment Survey, 1973 uses a national probability sample of persons 16 years old or older who are working for 20 or more hours a week. Three such separate surveys were conducted: in 1969-1970 (when it was named the Survey of Working Conditions), in 1973 and in 1977. The panel version used in this paper consists of all those among the 1455 individuals interviewed in 1972-73 who were re-interviewed in 1977. The information collected centers on many dimensions of the work environment with a view towards explaining the degree of job satisfaction of the respondents and also to build job quality indices. Of particular interest to us is a series of self-reported measures on many job characteristics, such as the level of creativity required by one's job, the degree to which the respondent's job is repetitive, the level of skills required by the job, etc. More particularly, we make use of the following questions:

1. "MY JOB REQUIRES THAT I DO THE SAME THINGS OVER AND OVER" (variable name: job is repetitive).

2. "I GET TO DO A NUMBER OF DIFFERENT THINGS ON MY JOB" (variable name: variety of things to do).

3. "I HAVE A LOT OF SAY ABOUT WHAT HAPPENS ON MY JOB" (variable name: worker has a lot of say about what happens on her/his job).

4. "I DETERMINE THE SPEED AT WHICH I WORK" (variable name: worker sets own pace).

5. "MY JOB REQUIRES THAT I KEEP LEARNING NEW THINGS" (variable name: job makes worker learn new things).

6. "MY SUPERVISOR IS SUCCESSFUL IN GETTING PEOPLE TO WORK TOGETHER" (variable name: teamwork).

Answers are scaled in the following way for the first five questions: 1: STRONGLY DISAGREE; 2: DISAGREE; 4: AGREE; 5: STRONGLY AGREE. We have re-coded the last two possibilities to 1 and the first two to zero. The scaling of the answers to the question about teamwork is: 1: NOT AT ALL TRUE; 2: A LITTLE TRUE; 3: SOMEWHAT TRUE; 4: VERY TRUE. Again, this variable is coded as 0 if the answer is 1 or 2 and to 1 if the answer is 3 or 4 .Turning now to the method of pay, unfortunately we have that information only for the 1977 interview. 
We know whether people are paid salaries, hourly rates, piece rates, or commissions. Summary statistics are reported in Table 1.

The answers to the job characteristic questions are used in the following fashion. We first use them directly as explanatory variables in our estimations. However, as explained in more detail below, we have to be worried about endogeneity and/or measurement error problems when using these variables. Thus, we also compute the average response per occupation category ( 20 such cells) for both the 1973 and 1977 interviews. ${ }^{1}$ We then use these averages both as instruments for the individual-level answers and directly as regressors. Figure 1 illustrates how responses to job characteristics vary by type of compensation. In figure 2 , we have averaged job characteristics by occupation, which deceases the variation in responses compared to figure 1, though there is still approximated $10 \%$ variation in response rates from highest to lowest for characteristics except "Set Own Pace". Table 2A shows the average of the job characteristics by occupation and Table $3 \mathrm{~A}$ shows the share of each pay method by occupation.

\subsection{National Longitudinal Survey of Youth (1988- 1990)}

The National Longitudinal Survey of Youth data set surveyed 12,686 young males and females who were between the age of 14 and 21 in 1979. In 1988, 1989, and 1990, respondents were asked whether all or part of their earnings were based on job performance. They were also asked a few questions on their work environment. For instance, we know if the respondents were supervising other employees and whether they had received a promotion since the last interview. Unfortunately, as is the case for the QES, we do not know the precise dollar amounts of incentive pay received by workers nor do we know the proportion of their earnings which is due to pay-for-performance.

The question pertaining to pay-for-performance is the following:

"THE EARNINGS ON SOME JOBS ARE BASED ALL OR IN PART ON HOW A PERSON PERFORMS THE JOB (HAND CARD D). ON THIS CARD ARE SOME EXAMPLES OF EARNINGS THAT ARE BASED ON JOB PERFORMANCE. PLEASE TELL ME IF ANY OF THE EARNINGS ON YOUR JOB (ARE/WERE) BASED ON ANY

\footnotetext{
${ }^{1}$ The QES contains many more questions on job attributes in addition to the ones used in this paper. One criterion for selecting the questions we use is that the question had to be asked in both the 1973 and 1977 interviews. This allows to use more observations to compute the group averages.
} 
OF THESE TYPES OF COMPENSATION. PLEASE DO NOT INCLUDE PROFIT SHARING OR EMPLOYEE STOCK PURCHASE PLANS.

1. PIECE RATES.

2. COMMISSIONS.

3. BONUSES (BASED ON JOB PERFORMANCE).

4. STOCK OPTIONS.

5. TIPS.

6. OTHER."

They were also asked whether they had received a promotion on their current/most recent job since the last interview. We should note that it is not possible to tell a priori whether the bonuses refer to amounts paid at the discretion of the employer when the latter subjectively considers that the performance of the employee is worthy of a cash reward, or whether they merely represent another form of piece rate. In the latter case, the employee gets a reward for achieving or surpassing some kind of quantitative target which can be objectively determined. Our results below suggest that bonuses are fundamentally different from piece rates as a form of compensation. Some summary statistics are presented in table 1.

We restrict the sample to individuals who were in the labor market on a full-time basis. The people who were considered as meeting that criterion were (i) those whose primary activity was either working fulltime, on a temporary lay-off or looking actively for a job, (ii) those who had worked at least half the year since the last interview and who were working at least 20 hours per week. Individuals excluded from the sample are those who have been in the military at any time, the selfemployed and all public sector employees. These restrictions leave us with an unbalanced sample of 8,165 observations (3,847 workers).

Concerning some aspects of the work environment, although no questions pertaining to the characteristics of the jobs were asked during the 1988-1990 period, such questions were asked in 1979 and 1982. More specifically:

"WE WOULD LIKE TO KNOW WHAT KIND OF OPPORTUNITIES THIS JOB OFFERS YOU. (FIRST/NEXT) HOW MUCH OPPORTUNITY DOES THIS JOB GIVE YOU (READ CATEGORY)- A MINIMUM AMOUNT, NOT TOO MUCH, A MODERATE AMOUNT, QUITE A LOT, OR A MAXIMUM AMOUNT? [CATEGORIES]

1. TO DO A NUMBER OF THINGS (VARIETY).

2. DEAL WITH PEOPLE.

3. FOR INDEPENDENT THOUGHT OR ACTION (AUTONOMY). 4. FRIENDSHIPS. 
5. TO DO A JOB FROM BEGINNING TO END (PROBE IF NECESSARY: THAT IS, THE CHANCE TO DO THE WHOLE JOB) (COMPLETE TASK)."

Answers are recoded to 0 if respondents answer either "A MINIMUM AMOUNT", "NOT TOO MUCH", or "A MODERATE AMOUNT", while they are recoded to 1 if respondents answered either one of the last two possibilities.

For each one of 20 occupation cells, we compute the average of the answers in both the 1979 and the 1982 surveys. We then merge these averages to each corresponding occupation category for the 1988-1990 period. This, of course, is a crude way of proxying the different dimensions of the jobs, but we think that it is not too unreasonable to think that jobs which are in the same occupation cell share some common characteristics. The variation in data is illustrated in figure 3 . Tables $2 \mathrm{~B}$ and $3 \mathrm{~B}$ provide more detailed summary statistics pertaining to the average characteristics by pay methods and by occupation, as well as the percentage of workers being paid either form of contract by occupation. Looking at these tables, a few empirical regularities seem to emerge. First, as suggested by figures 2 and 3 , it seems that occupations that require the workers to perform relatively fewer tasks are associated with piece rate pay schemes instead of straight salaries. On the other hand, jobs with a higher degree of autonomy seem to favor salaries over other forms of pay methods. We can see in Table 3B that operatives are the occupation category that relies the most on piece rates. At the same time, autonomy and variety of tasks is a less important feature of these types of job, as seen in table $2 \mathrm{~B}$.

Note that the local unemployment rate contained in the NLSY (as is the case with the PSID) is the measured at the level of the county. To further investigate the impact of labor market tightness on pay, we also make use of the industry-level unemployment rate, as computed by the Bureau of Labor Statistics.

\subsection{The Panel Study of Income Dynamics (1984- 1991)}

The sample consists of white male heads of households aged 18 to 64 with positive earnings for the period spanning the years 1984-1991. ${ }^{2}$ Individuals in the public sector and who worked less than 500 hours are excluded from the analysis. This leaves us with 10,803 observations. We

\footnotetext{
${ }^{2}$ In the PSID, data on hours worked during year $t$, as well as on total labor earnings, bonuses/commissions/overtime income, and overtime hours, are asked at the year $\mathrm{t}+1$ interview. Thus we actually use data covering interview years 1984-1992.
} 
know whether each worker is paid a piece rate, a commission, an hourly rate or a salary (the structure of the question pertaining to method of pay is very similar to the one in the QES).

One interesting feature of the PSID for the 1984-1991 period is the fact that we are able to determine whether a worker received a bonus over the last year. In the PSID questionnaire, workers are asked the amount of money they received from either working overtime, or from commissions, or from bonuses paid by the employer. Given that workers report their number of overtime hours worked as well as the hourly rate for overtime, we are able to compute an estimate of the amounts paid in bonuses. More precisely, the percentage of workers who receive a bonus which is reported in table 1 is calculated by dropping all workers paid commissions and by dropping all observations with a negative estimate $(294)^{3}$. Figure 4 illustrates the distribution of bonuses as a percentage of total labor income. As we can see, the distribution is heavily skewed with the vast majority of bonuses representing less than 10 percent of earnings.

Thus we have quite good measures concerning the form of compensation in this sample. However a serious deficiency of the PSID for our purposes is that we do not have information concerning job characteristics. We deal with this problem by supposing that jobs characteristics are similar within the same occupation cell. This assumption permits us to merge to the sample the group averages of the job characteristic measures computed with the QES with the PSID.

\subsection{The January 1977 Current Population Survey (Validation Survey)}

A subsample of the January 1977 Current Population Survey were asked questions about hours worked, union coverage, earnings, and also about pay methods in addition to the usual questions on labor force status, schooling, demographics, industry affiliation and occupational status. They were also asked to provide the address and name of their employers so that the same set of questions could be asked to them. To the best of our knowledge, this is the only instance in which such questions about contract form were asked. ${ }^{4}$ One disturbing result from the validation survey is the fact that employers and employees agree on oc-

\footnotetext{
${ }^{3}$ Since we cannot separately identify the amount of income derived exclusively from commissions, we have to remove these workers from the calculations. Note that removing all negative estimates of the bonuses probably biases the mean bonus paid upward.

${ }^{4}$ Mellow and Sider (1983) provide a thorough analysis of that data set.
} 
cupational status less than $84 \%$ of the time at the one-digit level and less than $60 \%$ at the three-digit level (more on misclassification errors below). Summary statistics are reported in Table 1. Note that those were computed using employees's responses. In the estimation section, we show the results both with employees' and employers' responses. As is the case with the PSID, the CPS questionnaire allows us to compute the average amount paid in bonuses. More precisely, employers (and workers) are asked whether the workers received any extra amount in addition to their regular pay. Although it is an imperfect measure of bonuses paid for individual performance, we use it to study the impact of sector-level unemployment on the incidence of such bonuses.

\section{Explaining the form of compensation}

The earlier studies reviewed in the introduction have focussed upon essentially two issues. The first is concerned with the way individuals self-select into occupations with different forms of compensations. This effect is not the focus of the current study, and we use the longitudinal aspect of the data sets to control for unobserved individual characteristics (discussed in detail below). The second issue is the size of the incentive effect, namely the elasticity of the effort supply of effort with respect to pay.

Our maintained hypothesis is that firms choose profit maximizing compensation policies, given the anticipated effect of these policies upon effort.Hence all pay is considered incentive pay. For example, even when a worker is paid a fixed hourly wage, continued employment is conditional upon satisfactory performance of one's duties. Hence if performance pay such as piece rates or commissions are not observed, this is because these are not cost minimizing solutions to the incentive problem. In this respect we follow Holmstrom and Milgrom (1994), who illustrate how the optimal employment contract varies with job characteristics.

To identify the relationship between job characteristics and compensation we follow the standard approach in the theory of the firm, and view capital as fixed in the short run, while prices are flexible. For example, a Japanese manufacturing plant may be explicitly designed to have runways above the plant floor where management can observe the actions of workers at a low cost. ${ }^{5}$ In terms of our data, one would expect the existence of such runways to result in workers reporting that they have less autonomy. Given the hypothesis that job characteritics are

\footnotetext{
${ }^{5}$ MacLeod observed this during a visit to one of Kabota's farm machinery plants in Japan.
} 
fixed in the short run implies that these are right hand side variables in our regressions, while the form of compensation is a left hand side dependent variable.

The choice of compensation is modelled as a hierarchial decision, permitting us to study the effect of job characteristics as a sequence of qualitative choice models. This greatly simplifies the econometrics and permits better control over selection effects. The starting point of the hierarchy is based upon the distinction between what we call Input based versus Output based compensation systems.

\subsection{Input versus Output Based Compensation}

From the literature on agency theory, particularly Holmstrom (1979), we know that optimal contracts should be conditioned upon objective measures of performance, with the quality of the match increasing with the quality of the performance measure. Thus if we let $e$ be worker effort, and $q$ is a measure of performance, we might write

$$
q=e+\varepsilon,
$$

where $\varepsilon$ is a random variable with zero mean and variance $\sigma^{2}$. The distinction between output and input based compensation is due to Lazear (1986), though we use the terms in a somewhat different way. An individual's input can be interpreted in a variety of ways, including time spent at a job, the number of calories expended, or the amount of thought put into a decision. We focus upon the ingredient that agency models emphasize is important, namely the ability of individuals to control the measure of productive output. Hence by an input based system, we mean one where the variance of $\varepsilon$ is low, and the worker can precisely affect his or her output measure. This would for example include piece rate systems where individuals can control the number of units produced, or time based compensation where time is the product, as in the case of say night-watch persons. Another way to think about input based systems, is that they correspond to the assumptions of a competitive labor market for labor. That is the firm contracts with the worker for a

well specified output, whether it is the time on the job or the number of pieces produced.

In our data we cannot directly observe the variance of measured output relative to effort. Rather, we take the view that workers on hourly wages or piece rates most closely correspond to input based compensation. With an hourly wage the workers are expected to produce a well defined output each hour. Salaried workers, those receiving commissions 
and bonuses are defined to be output based jobs. For example commission jobs are most common for sales persons, where one expects the relationship between effort and output to be very noisy. Regardless of the amount of effort, no sale is a sure thing until it is finalized, hence the link between effort and output is noisier. The actual commission rate will depend on a number of factors, including the risk aversion of the employee and the other instruments available to the firm. ${ }^{6}$ In the case of salaried workers, the hours of work are often imperfectly specified, with work demand varying from week to week. Hence we suppose that for these workers not only is there no low variance measure of output, but we also suppose that their output is non-contractible (more precisely defined below).

Though this classification is imperfect, as we shall see from the regressions, our results tend to support our interpretation. More specifically our strategy is for identifying the effect of job characteristics is to estimate a linear probability model of the form:

$$
c_{i j}=X_{i j} \beta+\sum_{k=1}^{K} \delta_{k} Z_{i j k}+\varepsilon_{i j}
$$

where $c_{i j}$ is the method of payment of worker $i$ in the occupation cell $j$, with $c_{i j}=1$ or 0 . In the case of Input versus Output based pay we assume $c_{i j}=1$ for the Input case. ${ }^{7}$ The vector $X_{i j}$ is a set controls such as experience and schooling, $Z_{i j}$ is a K-dimensional vector of job attributes, and $\varepsilon_{i j}$ is the error term. Our object is to find learn how measured characteristics, $Z_{i j}$, affect the incidence of a particular form of compensation.

When a good measure of output is available, then it is possible for the firm to write a complete contract that essentially decentralizes control to the worker. That is conditional upon the contract, the worker is able to decide how to execute its terms. In particular this implies that for example such workers would have greater autonomy, in the sense of direct supervisory input is less important. Also jobs that are repetitive, or have less variety, are likely to have better measures of worker input, and hence fall into the Input category.

Conditional upon being in the input or output based case, the firm can further refine the contract. The set of possibilities that we study can

\footnotetext{
${ }^{6}$ See Holmstrom and Milgrom (1994) for a detailed analysis of commission systems.

${ }^{7}$ Note that misclassification of pay methods by workers increases the variance of any estimated effect, as in any measurement error problem. Thus, the measured effects are likely to be less precisely estimated than would be the case when there is no error in the reported pay methods.
} 
be illustrated with a compensation tree, shown in figure 5 . The factors determining the refinement of contract form at each node are considered in more detail in the next three subsections.

\subsection{Hourly Wage versus Piece Rate}

By an input based system we mean for which there is a good measure of worker output. This does not necessarily imply that it is efficient to use incentive pay system. For example, as Holmstrom (1982) shows, in some situations the firm might use a forcing contract that consists of a fixed wage and a penalty should output fall below a certain level. Piece rates might be efficient if the underlying productivity of the machine used by the worker is unknown, then a piece rate contract would in principle give an incentive for the work to reveal the efficiency of the matching. However, as Gibbons (1987) argues, the ratchet effect may make such a system infeasible. Kanemoto and Macleod (1992) show that when the uncertainty arises due to unobserved worker ability, then competition for workers can eliminate the ratchet effect.

In that case piece rate contracts may be strictly preferred to forcing contracts when variations in worker ability are important. A good example of this is farm work, where children often participate in a harvest. In this case, piece rate contracts are efficient because it provides an incentive for more able workers to produce more, without requiring the manager to negotiate contracts as a function of the physical ability of each worker. This interpretation of piece rates is also consistent with the empirical work based on the selection model of Lazear (1986).

Even though worker effort may be measured at a low cost, there are cases where linear piece rate contracts may not be efficient. For example, the pace of work is highly regulated on modern assembly lines, and hence workers are not free to adjust effort as they wish. Rather all workers, regardless of ability, are required to achieve a certain level of competence to ensure there are no bottle-necks in the production process. The job characteristic that makes piece rates infeasible is the need to have a well defined set of tasks completed in a timely fashion. Moreover, in these cases the worker would have less control over the way they use their

time, since they are required to coordinate their activities with others (thus teamwork is also likely to be more important). In appendix 7.1 we show formally how the structure of the technology can affect the choice between a fixed wage forcing contract, and a piece rate contract. 


\subsection{Contractible versus Non-Contractible}

The output based side of the compensation tree corresponds to those jobs for which an accurate contractual measure of input or effort is not available. We would expect there to be variation in quality of measure

that would have implications for the type of contract used. In the case of sales persons, the level of sales, though noisy, is still a very good measure of worker performance. For these types of jobs, agency theory predicts the use of commission contracts that have rates that decrease with the variance of noise in the output measure and the level of risk aversion of the employee.

In other occupations, such as management jobs, contractible measures of output might be the level of division profits. Though these profits are likely to be positively correlated to manager effort, there are like to be many other variables that affect profits that make this measure only very weakly correlated to effort, and would therefore subject the manager to a great deal of undiversifiable risk. In these cases the firms must depend upon subjective measures of performance provided by the reports of supervisors (see Prendergast and Topel (1996)).

One issue is if ones supervisor can observe performance, what exactly makes it impossible to incorporate these reports into a formal contract? One reason, highlighted by Simon (1951) and Williamson (1975), is that the complexity of the employment relationship makes it impossible to use state contingent contracts. The details underlying this idea are formalized in MacLeod (1996), and summarized in appendix 1B. The main result is that when a job requires allocating effort among a number of different tasks in response to unexpected events, then writing a complete state contingent contract is impossible. Thus one expects the incidence of commission contracts to be negatively related to reported job characteristics such as the number of tasks in the job.

A solution to the problem of complexity is to use an ex post evaluation of the employee based upon supervisor reports. However contract incompleteness implies that the terms of the relationship cannot be enforced by a third part, and hence performance depends upon what Macneil (1974) calls a relational contract, dicussed in more detail in the next section. Given that direct supervision of the employee is an essential ingredient of the relational contract then workers in such contracts should have less autonomy, but also have well defined goals set by supervisions. This later case suggests that the variable "complete task" should have a positive impact on the likelihood that a relational contract is used. 


\subsection{Bonus Pay/Promotion versus Termination Con- tract}

When an explicit contract is not possible, then the firm must rely upon some form of ex post incentive to ensure performance. There are essentially three types of non-contracted ex post rewards:

1. Termination contract - pay the worker a fixed salary, and fire the worker at the end of the period if performance is not satisfactory. This is commonly known as an efficiency wage contract.

2. Bonus contract - pay the worker a discretionary bonus at the end of the period that depends on performance.

3. Deferred compensation - reward the worker with a promotion or permanent wage increase.

Between $10 \%-14 \%$ of the individuals in our data sets receive some form of bonus pay (as opposed to piece rates or commissions which are forms of complete contingent contract with no ex post evaluation). ${ }^{8}$ The theory developed in MacLeod and Malcomson (1989) makes some predictions concerning the effect of market alternatives for workers upon the incidence of bonus pay that we briefly outline here.

Suppose the employment contract is given by $c=\{w, b\}$, where $w$ is a fixed wage that is paid at the end of the period regardless of performance, and $b \geq 0$ is a discretionary bonus payment that depends on the firm's informal ex post evaluation of performance. Given this contract the individual utility and firm profits are given by:

$$
\begin{aligned}
& U(c)=w+b-v e+\delta U^{c}, \\
& \Pi(c)=\theta e-w-b+\delta \Pi^{c},
\end{aligned}
$$

where $e \in\{0,1\}$ is a non-contractible effort choice taken by the worker, $U^{c}$ and $\Pi^{c}$ are the utility and profit respectively from continuing the relationship. The parameters $v$ and $\theta$ are respectively the cost and benefit of one unit of effort.

Given this contract, the implicit agreement between the firm and worker requires the firm to pay the bonus if and only if the worker selects the high level of effort. ${ }^{9}$ Should either party shirk, then the

\footnotetext{
${ }^{8}$ Some individuals in the NLSY data receive both piece rates and bonuses. However they are a small fraction of our sample and so we do not explicitly consider this case.

${ }^{9}$ MacLeod and Malcomson (1989) prove that there is no loss of generality when contracts are restricted to take this form.
} 
relationship is terminated immediately. Letting $\bar{U}$ and $\bar{\Pi}$ denote the market alternatives for the worker and the firm then a contract is selfenforcing if and only the following incentive conditions are satisfied:

$$
\begin{aligned}
& \delta\left(U^{c}-\bar{U}\right) \geq v-b \\
& \delta\left(\Pi^{c}-\bar{\Pi}\right) \geq b .
\end{aligned}
$$

Notice that it is necessary to pay a bonus only if $\delta\left(U^{c}-\bar{U}\right)<v$. For example if unemployment rates for the worker were to increase, this would lower $\bar{U}$, and increase the likelihood that $\delta\left(U^{c}-\bar{U}\right) \geq v$. In this case the threat of termination alone provides sufficient incentives for the worker not to shirk. Conversely, with a tight labor market, when the worker can always find alternative work easily, the incentive constraints imply that some form of end of the period bonus must be paid. Therefore we expect the incidence of bonus pay to be a decreasing function of the worker's unemployment rate.

In this model we have assumed that the supervisor can perfectly observe performance ex post. We could add imperfect observability, as in Shapiro and Stiglitz (1984), and obtain essentially the same result. It is sometimes mistakenly thought that it is imperfect observability that generates an efficiency wage. However, as the results of Holmstrom (1982) demonstrate, an imperfect but contractible measure of output would completely eliminate the equilibrium unemployment result for a standard efficiency wage model.

\subsection{Overview of Estimation Methodology}

In summary, we view the choice af compensation form as a hierarchial decision that depends upon several job attributes. To explore how these job attribute affect compensation we estimate a sequence of binary choice models based upon the four trade-offs discussed above:

1. Output versus Input Based Contracts (O vs. I)

(a) Input based contracts are more likely when firms have good, contractible, measures of worker effort.

2. Hourly versus Piece Rate Contract (H vs. PR).

(a) When workers are required to tailor effort to the speed of the machine then we expect to see more forcing contracts (which are identified with fixed wage contracts). 


\section{Contractible versus Non-Contractible Performance (C vs. NC)}

(a) The contractible case correspond to an explicit contract, where the employee has autonomy, but faces some risk due to noise in the performance measure. If there is multi-tasking then an incomplete contract combined with subjective performance evaluation is used.

4. Bonus/Promotion+Salary versus Termination+Salary Contract (B vs. T)

(a) In this non-contractible case one expects bonus pay to be used when the employee has good market alternatives.

We assume that the latent variables affecting these choices are independent, and examine the robustness of this assumption using a Hausman test. We now describe in detail our procedures for each of the data sets.

\subsection{QES Data}

Consider the following linear probability model:

$$
c_{i j}=X_{i j} \beta+\sum_{k=1}^{K} \delta_{k} Z_{i j k}+\varepsilon_{i j}
$$

where $c_{i j}$ is the method of payment of worker $\mathrm{i}$ in the occupation cell $j$, with $c_{i j}=1$ if worker $i$ is paid a salary and $c_{i j}=0$ if he is paid on hourly basis, for example. $X_{i j}$ is a vector of controls such as experience and schooling, $Z_{i j}$ is a K-dimensional vector of job attributes, and $\varepsilon_{i j}$ is the error term. The problem with using the self-reported measures for worker $i$ is easily seen if we consider that the measure $Z_{k}$ can be decomposed in the following way:

$$
Z_{i k}=\widehat{Z}_{i k}+\alpha_{i}
$$

where $\widehat{Z}_{i k}$ is the "true" value of attribute $\mathrm{k}$ of worker $i$ 's job and $\alpha_{i}$ can best be seen as a measurement error. ${ }^{10}$ If we had multiple observations

\footnotetext{
${ }^{10}$ Note that instead of directly using the (scaled) reported measures of the job attributes, we construct a 0-1 variable from those answers. Thus, the measurement error problem is really a misclassification error problem. That is, with a $0-1$ variable, there are jobs which are reported as being characterized by, say, few tasks when the opposite is true, and vice versa.
} 
per individual and the $\alpha_{i}$ 's were invariant within workers, then equation (7) could be estimated in first difference and we would recover the true effect $\delta_{k}$. If instead $\alpha_{i}$ is just a random (misclassification) error, then differencing would just add noise which would increase the bias in the estimated parameter. Note that if $\varepsilon_{i j}$ contains an individual-specific component which is correlated with $\alpha_{i}$, thereby biasing the OLS estimate of $\delta_{k}$, then differencing would eliminate this bias. ${ }^{11}$ We can deal with both the problem of measurement error and with the problem of biases caused by the possible correlation between the unobserved individualspecific terms in equation (8) and equation (7) if we can find a suitable instrument for $Z_{i k}$. The instrument we construct is the average value of $Z_{i k}$ computed for all workers in worker $i$ 's occupation cell. Note that we exclude worker i's own reported value of $Z_{j k}$. Thus, by construction, the instrument called $\bar{Z}_{j k}$, the average value of job attribute $Z_{k}$ in occupation cell $j$ is not correlated with $\alpha_{i}$ in equation (8). By using a group-level variable though, we create another problem. If workers in cell $j$ share an unobserved component of variance, then residuals from the OLS or IV estimation of (7) will be correlated within each cell. As shown in Moulton $(1986,1990)$, the precision of the estimated coefficient of a group-level variable can be seriously downward biased when using OLS, even though the estimated coefficient is not. In other words, the estimated group effect is not as precisely estimated as the unadjusted standard errors would lead us to believe. The same problem presents itself with instrumental variable estimation (see Shore and Sheppard (1996)). In the reported results, all standard errors are adjusted to take into account the group structure of the explanatory variable (more details below). Because we have to rely only on group averages when using the NLSY, the PSID, and the CPS, we also use the group averages directly instead of using them as instruments in some of the specifications. Not surprisingly, the results using IV are usually similar to those where we directly use the group averages as explanatory variables. ${ }^{12}$ The only major discrepancy between the IV results and the results using group averages is on the contractible vs. non contractible portion of the deci-

\footnotetext{
${ }^{11}$ For example, letting $\epsilon_{i j}=\mu_{i}+v_{i j}$, if low $\mu$ workers tend to be paid on an hourly basis and at the same time tend to exagerate a given attribute of their job, such as variety of tasks, then the negative correlation between $\mu$ and $\alpha$ would cause $\delta^{O L S}$ to be downward biased.

${ }^{12}$ Note that if we were computing the group averages using only the observations from the 1977 sample that we use in our regressions instead of averaging all answers from the 1973 and 1977 surveys, the IV estimates would be identical to the grouped data estimates. Thus, the fact that the IV results differ from the results using group averages stems from the fact that we are computing the group averages using both the 1973 and 1977 data while we are only using the 1977 data for estimation purposes.
} 
sion tree. Note also that in the case of the IV estimation, we provide an ex-post correction to the standard error of the parameters computed with OLS instead of using the two-step methodology employed with the group averages (see Shore and Sheppard (1996) for details).

\subsection{NLSY, PSID, and CPS Data}

To deal with the problem of structural group effects, we make use of the following "two-step" procedure. In the case of a linear model, this amounts to first regressing the dependent variable on all individualspecific regressors as well as on a full set of dummy variables, one for each occupation cell. In the second stage, we use the estimated parameters associated with the group dummy variables as the dependent variable and regress this variable on group-level regressors, in our case the job characteristic measures. This procedure insures that the coefficient standard errors fully account for the group structure of the regressors. Note that this approach is also suitable for estimation with non-linear techniques (Borjas and Sueyoshi $(1994)^{13}$ ).

Succinctly, consider the following latent variable model:

$$
Y_{i j}^{*}=X_{i j} \beta+Z_{j} \delta+\mu_{j}+\epsilon_{i j}
$$

where $\mu_{j}$ represents the random group effect, $i=1, . ., N$ indexes the individuals and $j=1, . ., M$ indexes the groups. We only observe an indicator variable $Y_{i j}=1\left(Y_{i j}^{*}>0\right)$. If we estimate model (9) using standard statistical packages, the reported standard errors may be severely downward biased if $\mu_{j}$ plays a significant role. Letting

$$
d_{j}=Z_{j} \delta+\mu_{j}
$$

where $d_{j}$ represents the total group $j$ effect, the procedure consists of first estimating model (9) replacing the group-level variables with an unrestricted set of dummy variables, one for each group. In the second stage, the estimated parameters associated to the dummy variables, the

\footnotetext{
${ }^{13}$ Provided that the number of individual per group is "large enough", Borjas and Sueyoshi show that the first-stage dummy coefficients can be estimated consistently using a fixed-effect probit model. Then, the second stage regression (GLS-taking into account the estimator variance of the first-stage probit) of these parameters on the group variables gives the correct standard errors. Although we do not report the results here, we have also estimated all models with a sequential logit. Outside from the different scaling of the parameters, results are very similar, especially with respect to the job attributes. Our choice of a linear approach stems from the possibility of controlling for unobserved heterogeneity in a straightforward fashion when using the NLSY and PSID data. Note that we make use of the logit method when testing whether the sequential approach is appropriate. More details are given in Section 6.
} 
$\widehat{d_{j}}$ are regressed on $Z_{j}$ (and a constant) taking into account the estimator variance computed in the first stage.

The same procedure is used in first-differences with the two longitudinal data sets that we have. That is, we estimate the occupation dummy coefficients in first-differences to control for unobserved labor quality, and then we project the resulting estimates on the average job characteristics. It is important to note that while using first-differences does allow us to control for fixed unobserved worker attributes, this procedure does not control for worker self-selection into an occupation following transitory or permanent shocks in the worker's previous occupation. In addition it does not control for selection problems stemming form occupational matching considerations. More on that problem below.

When we investigate the role of industry-level labor market conditions on the incidence of bonuses, we use the same methodology by first regressing the contract choice variable on a full set of year $\mathrm{X}$ industry dummies (1 digit). In the second step, we use the coefficients estimated in the first step as explanatory variables and regress them on the corresponding industry unemployment rate as well as on year and industry dummies. Having just one year of CPS data, our first step whith that data set consists of regressing the contract choice variable on just the nine industry dummy variables. The resulting coefficients are then projected on a constant and the corresponding industry's unemployment rate.

\subsection{Misclassification Errors}

Because our estimation strategy relies on occupation categories to identify the effect of job characteristics, we have to be worried about workers reporting their occupation with error. Indeed, as shown in Mellow and Sider (1983), the degree of mismatch between workers' and employers' responses on occupational status is significant: about $18 \%$ at the onedigit level and over $40 \%$ at the three-digit level. ${ }^{14}$ Thus to provide correction for the rate of misclassification, we make use of two estimators. When working in first-differences, we directly use the Krueger and Summers (1988) estimator, which was developed in the context of industry misclassification. Then, in levels, we adapt the Krueger and Summers estimator and apply it to all the data sets. One shortcoming of that estimator is the fact that it requires orthogonality between the occupation dummies and the other regressors. Of course this is a questionable assumption, both in first differences and especially in levels. However,

\footnotetext{
${ }^{14}$ The mismatch rate for industry affiliation is a little over $7 \%$ at the one-digit level and about $16 \%$ at the three-digit level.
} 
it turns that many of our results concerning the impact of job characteristics without correcting for misclassification errors are robust to the exclusion of all the other explanatory variables. ${ }^{15}$ Thus we think that the results in levels accounting for misclassification are useful. Also, the Krueger and Summers estimator adapted for levels is very useful to compute consistent estimates of the average job characteristics. Details are given in Appendix 2. ${ }^{16}$

\subsection{Endogeneity Problems}

Even though we control for unobserved time invariant worker attributes when we use both the NLSY and the PSID, we have to be worried about other selection issues. Specifically, it may be that occupational matching considerations bias the results reported below. ${ }^{17}$ This would happen if the average reported job characteristics were systematically correlated with the occupation-match quality. For example, suppose that some workers choose to work in occupations where they are more likely to be paid a piece rate because of comparative taste or economic advantages. Suppose also that for some reason the quality of the occupation match is negatively correlated with the number of tasks in these occupations. Then if multi-tasking is found to impact negatively upon the probability of being paid a piece rate, this result could simply reflect the effect of the unobserved occupation match quality and the measured effect of multi-tasking would therefore be downward biased.

One way to deal with this problem would be to have variation in the reported job characteristics within occupation-matches. Then, a simple fixed-effect estimator using only within match variation would identify the causal effect of the attribute. Unfortunately, that approach is not applicable with our data given that we have no variation over time in the measured job characteristics.

Instead, we borrow from recent work by Dahl (1997) who develops

\footnotetext{
${ }^{15}$ What that means is that even when we control for individual characteristics, we essentially reproduce the patterns that are present in the sample means, such as those shown in Table 2 and 3.

${ }^{16}$ In $\mathrm{M} x 2$ contingency tables, where $\mathrm{M}$ refers to the number of subgroups (i.e. occupations), if the binary outcome variable $\mathrm{A}$ is subject to misclassification errors, then the estimated difference in proportions between each of the subgroups is unambiguously attenuated towards zero. Note that for this to be true, misclassification errors have to be nondifferential with respect to the polytomous variable B defining the subgroups. In other words, the probability of A being misclasssified has to be the same for each of the subgroups in B. See Kuha and Skinner (1995) for a survey on categorical data analysis.

${ }^{17}$ On the subject of occupational or career matching, see, for example McCall (1990) or Neal (1996).
} 
and applies a semi-parametric correction technique for sample selection in the context of a multi-market Roy model of mobility and earnings. Combining Lee's $(1982,1983)$ results on maximum order statistics in the context of polychotomous choice models and recent work by Ahn and Powell (1993) on semi-parametric "single index" models, Dahl shows that accounting for the endogeneity of the migration decision from state of birth to state of residence substantially affects the estimated return to schooling by state of residence.

In the context of our paper, migration occurs from occupation to occupation. In essence the contract choice equation taking into account selection can be written as

$$
c_{i j k}=X_{i j k} \Gamma+O_{i j k} \beta_{k}+\lambda\left(p_{i j k}\right)+u_{i j k}
$$

where $\lambda\left(p_{i j k}\right)$ is an unknown selection correction function of the single index $\mathrm{p}_{i j k}$ which represents the probability of moving from occupation $\mathrm{j}$ to occupation $\mathrm{k}$. To approximate $\lambda($ ), we use a cubic function of the different "migration" probabilities while the migration probabilities are computed by schooling (4 categories) X experience ( 4 categories) cells ${ }^{18}$. The three terms are then added as regressors in the contract choice equation. While details of this technique are given in Appendix 2, one of the main advantages of using a semi-parametric selection correction method is that it allows for a non monotonic correction function, whereas usual parametric methods (e.g. Heckman's two-step procedure or its generalization to polychotomous settings) impose monotonicity.

\subsection{Other Data Problems}

Unfortunately, the group averages of the job characteristics computed with the QES show substantial multicollinearity, thus essentially preventing us from using all of them in each specification, unless we drop the constant. Consequently, we chose to use pairs of variables on the basis of their theoretical relevance. As is often the case with multicollinearity, the results are sensitive to the specification used. Note that the estimated constant is almost never statistically different from zero in any of the regressions used, even with only two average job attributes as regressors. It may then be tempting to simply drop it and perform the estimation on all the variables. Doing it produced results that are qualitatively similar to the ones reported here. However, we prefer to pick the

\footnotetext{
${ }^{18}$ Using higher order terms (to improve upon the accuracy of the approximation) did not change the results. On the other hand, a quadratic was sometimes too restrictive in its ability to pick up the non linearity of the selection effect.
} 
variables that we think should play a role on the relevant portion of the decision tree. Since the problem of multicollinearity is less severe with the NLSY job attribute measures, we include all of the NLSY average attributes in every regression.

\section{Results}

\subsection{Quality of Employment Survey}

Tables 4 and 5 report the results from estimating linear probability models for four cases. We do not have data on bonus pay, and hence do not report the B vs. T trade-off. Focusing on the impact of job characteristics, we can see that using individual-level responses produces substantially smaller estimates, although they are more precisely estimated than the instrumental-variable or group-level estimates. Note the similarity of the estimated coefficients when using IV or group-level data.

The I vs. O choice is affected only by the "job is repetitive" variable, which has the expected positive sign, and is significant in tables $4 \mathrm{~A}, 4 \mathrm{~B}$ and 5 . That is for repetitive jobs payment by the hour or by piece rate is more likely. The value of this result is to provide support for our first binary choice on the hierarchy emphasizing the distinction between wage and salary jobs. It is not surprising that the union variable is positive, since wage earners are more likely to be unionized. Another way to view the union effect is that unions are more important for jobs that require an explicit employment contract. The education and demographic characteristics are also significant and of the expected sign.

The choice $\mathrm{C}$ vs. $\mathrm{NC}$ is negatively affected only by the "variety of things to do" variable, and positively by the "Worker has a lot of say" variable, though both coefficients are significant only in the grouped averages, shown in table $4 \mathrm{C}$. The "variety of things to do" variable is a direct measure of the amount of multi-tasking, for which our theoretical model implies that a larger number of tasks is associated with less explicit contracting. The negative sign of this coefficient is consistent with this model. The other variables are too imprecisely estimated to have significant effects. As mentioned earlier though, the IV estimation results differ from the ones which are obtained from directly using the average characteristics by occupation. With IV, we find no evidence of a significant negative effect of multi-tasking on the probability of being paid a commission.

The $\mathrm{H}$ vs. $\mathrm{PR}$ choice is more or less affected by the same variables that affect the $\mathrm{C}$ vs. $\mathrm{NC}$ choice. One difference is in the effect of team- 
work on the probability of being paid a piece rate. With the occupation averages as the regressors, we find that teamwork is strongly negatively correlated with the use of piece rates. On the other hand, worker freedom to set his or her own pace on the job is found not to have any significant impact. The sign of the "Worker has a lot of say" is positive, which means that workers on piece rate contracts feel that they have more say on their jobs. This is consistent with viewing performance pay, such as piece rate contracts, as a form of decentralized decision making that allows the worker to set their own pace. This also is consistent with viewing wages as forcing contracts, where workers to meet the same standards and thus would report having less say in about their jobs.

As we can see in table 5, the results correcting for misclassification errors are very similar to the ones with no correction.

\subsection{National Longitudinal Survey of Youth}

Using the NLSY we are able to examine the effect of a number of job characteristics upon all four choices described in the compensation tree. Only the results using fixed-effects are reported here in table $6^{19}$. Note that the I vs. O choice is affected by all job characteristics. The variable "Autonomy" and "Deal With People" have a negative effect on the probability of using a Input based compensation system, as one would expect. The variable variety has a positive effect, which seems puzzling since one would expect variety to increase measurement problems, and hence increase the likelihood of an output based contract. This result highlights one of the problems we face using survey data of this type where respondents are not comparing job characteristics across different categories, but rather report their views concerning job characteristics.

The effect of the "Friendship" variable, although somewhat smaller in absolute value compared to the "Autonomy" variable, is quite large and significant, though of the opposite sign. This variable has economic significance in that the making of friends is a form of specific investment by the worker that tends to reduce turnover, and hence may be encouraged by firms using fixed wage contracts (Becker (1975)).

\footnotetext{
${ }^{19}$ Note that we also tried handling unobserved heterogeneity using Chamberlain (1980)'s conditional logit approach. The main problem with the use of this methodology is that all observations involving no change in the pay method from year to year have a zero contribution to the likelihood function. Thus, identification of the parameters relies exclusively on those individuals who do experience changes in pay method. With only three years of data, this represents a major constraint. For example, in the case of workers being paid either an hourly rate or a piece rate, using Chamberlain's method results in deleting over $60 \%$ of the 3927 observations. For that reason, we chose no to use it.
} 
In the case of $\mathrm{C}$ vs. $\mathrm{NC}$ the "Autonomy" and the "Variety" variables are significant, with the expected signs. The effect of the "Variety" variable has the same sign and is of the same order of magnitude as the corresponding parameter for the QES. With complete contracting, as we discussed in the case of piece-rates for the QES, we would expect this variable to have a negative sign.

The the incomplete contracts model suggests that the B vs. T choice is determined solely by labor market conditions. Moreover, an increase in the unemployment rate should result in an decrease in the use of bonus pay, results that are consistent with the evidence in table $6 \mathrm{~A} .{ }^{20}$ One might argue that this effect is due to rent sharing between the workers and the firm. However, our results concern the incidence of bonus pay. Under an optimal rent sharing arrangement one would expect to observe bonus pay each period, with only the size varying over the business cycle. It is also interesting to note that the size of the effect increases when we control for fixed effects. ${ }^{21}$ This is consistent with the fact that the pool of employed workers may be of higher average ability when unemployment is high. Assuming that higher ability workers are more likely to be paid bonuses, then the positive correlation between the local unemployment rate and unobserved ability implies that the estimated unemployment rate effect would be upward biased (i.e. in our case biased toward zero).

Secondly, the rent sharing model would predict that the industry unemployment rate, rather than the local unemployment rate would be more significant. This is because the industry unemployment should be more highly correlated to firm profits, and hence the likelihood that the firm shares the rents with the worker. That fact that it is the local unemployment rate that is most significant suggests that it is worker alternatives that is affecting the use of bonus pay, rather than firm profits.

Notice that the effect of local unemployment has the opposite effect for the $\mathrm{H}$ vs. $\mathrm{PR}$ choice. This is evidence that piece rates and bonus pay are used for fundamentally different reasons. ${ }^{22}$ Higher quality workers are less likely to face a layoff in a downturn (Gibbons and Katz (1991)),

\footnotetext{
${ }^{20}$ Note that the standard errors are not adjusted for group effects even though the local unemployment rate evidently has a group structure. The reason is that application of the two-step method is impractical given the small sample sizes we have to deal with. In other words, it is impossible to estimate separate dummies for each county, given that in many cases, we have only one observation per region (county). To use that methodology would require a sample of the size of the Current Population Survey. Of course, in the limit, if we had only one observation per region, then the group-level variable problem would not be relevant.

${ }^{21}$ In levels, the effect of the local unemployment rate on the probability of receiving a bonus is -0.0123 (standard error: 0.0032).

${ }^{22}$ Parent (1997) also finds evidence that piece rate and bonuses are different in the NLSY using a standard wage equation approach.
} 
hence the positive coefficient is also consistent with Lazear (1986)'s self selection story. In this case a positive coefficient arises due to the great fraction of high quality workers in the pool of employed during a local downturn. Another possibility is that the inherent flexibility of piece rate pay implies that these workers are less likely to lose employment during a downturn. Hence it may be the case that contract form has an effect on job tenure and turnover.

\subsection{Panel Study of Income Dynamics}

The results for the PSID are reported in table 7. This data is much noisier since the job characteristics variables are constructed by merging the QES data with the PSID by occupation cell. The "Variety" variable has a negative effect on the $\mathrm{C}$ vs. NC as observed for both the QES and the NLSY, an outcome that is consistent with the multi-tasking model. It also has a negative effect on the $\mathrm{H}$ vs $\mathrm{PR}$ trade-off, although it is not as precisely estimated. Again, correcting for misclassification does not markedly change the results. If anything, as is the case with all the data sets, it reinforces them.

Although not reported here, in the absence of controls for fixed effects the unemployment rate has the expected negative effect upon the $\mathrm{B}$ vs. $\mathrm{T}$ choice. However this result is no longer significant when we include fixed effects. In fact, the coefficient's p-value increases to 0.16 . This comes as a bit of a surprise given the results we get with the NLSY using fixedeffects. There we saw that the coefficient actually increases substantially once we control for unobserved heterogeneity. However, we should note an important factor which may help to explain the result we get with the PSID. Contrary to the NLSY where respondents were directly asked whether they had received any bonuses based on job performance, the measure we construct with the PSID results from using several answers: one about the total amount paid in bonuses, commissions and overtime; another about total labor earnings; and one about hours of overtime work. It is plausible that measurement error problems are worse for this constructed measure than is the case with the NLSY measure. ${ }^{23}$ Thus, to the extent that this is true, we would expect that using fixed-effects would substantially increase the noise-to-signal ratio. The results we have are certainly consistent with such a pattern.

Perhaps more importantly, the bonus measure derived from the PSID may include income from profit sharing plans. Remember that workers answering to the bonus question in the NLSY were explicitly asked to

\footnotetext{
${ }^{23}$ Recall that all observations for which the estimate of the bonus paid was negative are deleted.
} 
exclude such plans, as well as stock purchase plans. Separate questions were asked about those plans. To see if the possible presence of profit sharing in the PSID bonus measure might contribute to the weaker effect of the local unemployment rate, we ran a regression with the NLSY where we included positive answers to the question on the existence of a profit sharing plan. It turns out that the estimated coefficient dropped by about $30 \%$ in absolute value while still remaining significantly different from zero. Thus, it appears that the plausible presence of income from profit sharing plans in the PSID bonus measure might partly explain the weaker estimated link between local labor market conditions and the incidence of bonuses or promotions.

As with the NLSY, drastic sample size reductions prevent us to use Chamberlain's fixed-effect logit, except in the case of workers receiving a bonus or a salary where we lose just under $22 \%$ of the relevant subsample. As it turns out, results (not shown here) are very similar to those obtained with a linear model.

\subsection{Current Population Survey}

Table 8 shows the results using the workers' responses while Table 9 does the same with the employers' responses. The main difference between the two sets of estimates regards the effect of the industry unemployment rate on the probability of receiving a bonus. While the results using the employers' answers are essentially consistent with our previous results using the NLSY and the PSID, the link between labor market conditions and the incidence of bonuses is certainly not as convincing when we use the worker's answers to the Earnings Supplement. But on the whole, results are again rather similar to what we get from the other data sets, including the effect of correcting for misclassification errors.

One of the more robust results across our data sets is the fact that worker autonomy or worker having a lot of say in her or his job is strongly associated with the use of contractible performance contracts (commissions or commissions + salary). That particular result is consistent with Holmstrom and Milgrom (1994)'s idea that high-performance incentives and worker freedom from direct controls can be complementary instruments for motivating workers.

\subsection{The Effect of Occupational Self-Selection}

To save space, we do not show the results without the selection correction terms. We just note that taking into account occupation self-selection does not change them appreciably, even if in some cases the selection 
terms are strongly significant. Interestingly, the data set for which selection seems more important is the NLSY. For these young workers who are in the process of finding a good occupation match to a greater extent that the older PSID and QES workers, the selection terms are often significant, even though they appear not to be strongly correlated with the occupation average job attributes. ${ }^{24}$ Note also that we exploited the fact that we observe the NLSY workers' occupation when they first entered the labor market to compute the migration probabilities. We then used these probabilities for each worker's first observation (and only that observation) in the interval 1988-1990 to check on the robustness of the results. The idea is capture the fact that the match gain of moving from the first occupation to the present one is likely to be larger than it is when we compare occupation switching in adjacent years. Although not shown here, results are again qualitatively very similar to the ones without control for the endogeneity of the occupational choice.

\section{Testing the Appropriateness of the Hier- archical Structure}

The assumed sequential decision process facilitates the estimation of the relationship between job attributes, which we view as being exogenous, and the form of compensation. Testing one particular tree structure is very problematic as there is no obvious way to come up with an "appropriate" alternative (in fact there are $8 !=40,320$ ways to organize the different contract forms on this tree, thus theory is important in suggesting how to proceed with the estimation). We impose a particular hierarchy as an appealing way of decomposing the choice of contract form into the broad elements that characterize such choice. Nonetheless, a necessary condition for a sequential estimation methodology to be an adequate procedure is that the stochastic factors which influence contract choice on one portion of the tree be independent of the stochastic terms on other portions. ${ }^{25}$ This essentially amounts to testing whether the so-called Independence from Irrelevant Alternative (IIA) assumption holds. To do so, we perform a series of Hausman tests ${ }^{26}$ on each data set. Under the null hypothesis that the IIA assumption is true, then the parameters estimated by a multinomial logit with the full set of alter-

\footnotetext{
${ }^{24}$ Since we only observe a cross section of the CPS workers, it was not possible to apply the semi-parametric technique discussed above. Application of the technique requires that we know the workers' previous occupation.

${ }^{25}$ See Maddala (1983), pp. 49-51.

${ }^{26}$ See Hausman and McFadden (1984).
} 
natives are consistent and asymptotically efficient while the parameters estimated from a restricted subset of alternatives are consistent but inefficient. Let $\widehat{\beta}_{1}$ be the estimated parameter vector from the restricted choice set with $\widehat{V}_{1}$ its associated covariance matrix while $\widehat{\beta}_{2}$ and $\widehat{V}_{2}$ are defined likely for the full choice set, ${ }^{27}$ then

$$
H=\left(\widehat{\beta}_{1}-\widehat{\beta}_{2}\right)^{\prime}\left[\widehat{V}_{1}-\widehat{V}_{2}\right]^{-1}\left(\widehat{\beta}_{1}-\widehat{\beta}_{2}\right)
$$

is asymptotically distributed as $\chi^{2}$ with degrees of freedom given by the dimension of the parameter vectors. If $H$ exceeds its corresponding critical value, then we reject the IIA assumption. If it does not, then we cannot conclude that we have the correct structure, only that a sequential estimation procedure might be appropriate. Table 10 presents the results of those tests. As we can see, we cannot reject the hypothesis that the IIA assumption is acceptable for the three data sets. Again, we must emphasize that this does not confirm that this tree structure is the right one, only that it is not unreasonable to view the decision process as being made sequentially.

Note that in many cases the Hausman test statistic turns out to be negative ${ }^{28}$. To circumvent this problem, we also use the likelihood ratio test proposed by Small and Hsiao (1985). Their procedure guarantees apositive test statistic. As we can see, for all the data sets with the possible exception of the PSID, a sequential analysis does not seem unreasonable as all test statistics' p-values are fairly large. As for the PSID and the value of the test statistic in the first row of Table 10, one possible explanation could be that we are merging external information on job characteristics that may be a poor substitute for the "true" attributes. This is especially true since the QES information on job characteristics dates back to 1977 whereas the earliest PSID wave used in this paper is from 1984. Given that jobs evolve over time, this imperfect control for observable characteristics could make the residuals from the contract choice models correlated. Then, it would not be surprising that we have a harder time accepting the null hypothesis of independence with the PSID than is the case with the other data sets. To check that conjecture, we performed Hausman tests on the QES and NLSY excluding all job attribute measures. It turns out that the test statistics are of the same magnitude as the ones reported in Table 10. Thus, it does not seem

\footnotetext{
${ }^{27} \beta_{1}$ corresponds to the vector of parameters that are identified in both models i.e. its dimension is the same as that of $\beta_{2}$.

${ }^{28}$ This occurs because the weighting matrix fails to be positive definite. When Hausman and McFadden use an asymptotically equivalent matrix that always guarantees a positive statistic, in all cases they cannot reject the null hypothesis.
} 
to be the case that the results for the PSID are caused by including poor controls for observed characteristics.

\section{Conclusion}

In this paper we began with the hypothesis that compensation is some form of incentive pay, and the form of that compensation takes is the result of firm choosing the cost minimizing package conditional upon job characteristics. We have explored the interaction between job characteristics and contract forms, including wage and salary employment, the use of discretionary bonuses, piece rates and commission contracts, and have found evidence that job characteristics do have an impact upon the form of compensation used in practice. Our main result is that we have found both the agency theory and incomplete contract theory useful both for our estimation strategy and for interpreting our results. Despite the many imperfections in our data, the results are quite consistent over the four data sets that we use.

Two empirical results stand out. First we find that both piece rate and commission contracts are associated with the worker reporting more autonomy or control over his or her job. Thus one of the benefits of explicit incentive pay is that it effectively decentralizes decision making to the employee. It also has the implication that those workers who are not receiving incentive pay of this type are being more closely monitored, a result that is consistent with fixed wage or salary contracts providing incentives through some form or delayed punishment or reward system, a result that is consistent with an incomplete contracts model. In the case of salaried workers, the incomplete contract model finds further support with the result that the incidence of bonus pay is negatively correlated with the local unemployment rate.

Of course these results are tentative. In addition to the data problems discussed above, these data sets do not have information concerning other incentive systems known to be important, in particular incentives that are provided through tournaments (Lazear and Rosen (1981)) and promotion ladders (Carmichael (1983), Rosenbaum (1984)), issues that we hope will be addressed in future work. 


\section{Appendix 1}

\subsection{Fixed Wage versus Piece Rates}

The tradeoff between technology and matching to worker ability can be illustrated formally as follows. Consider a job where the worker is paid a wage $w$, and supplies input/hour of $q=\theta e$, where $e$ is the effort of the worker, and $\theta \in[\underline{\theta}, \bar{\theta}]$ is the ability of the worker with probability distribution $f(\theta)$. Let $U(\theta)$ denote the utility that a worker of ability $\theta$ receives on the job market, assumed to be a differentiable and increasing function of $\theta$. The utility function of the worker is given by $U(w, e)$, which is assumed to have the standard properties. ${ }^{29}$

For simplicity, assume that the firm is able to sufficiently screen workers so that all workers in range $[\underline{\theta}, \bar{\theta}]$ are employable, and would accept a job offered if offered to them. The major motivation for piece rates is that this screening process is imperfect, and hence it is not possible for the firm to tailor expected output to the characteristics of the worker. Moreover, in practice worker productivity is time varying, for example due to changes in health status.

The effect of worker effort on output is modelled with the following sigmoid production function defined by:

$$
Q=g(q, \rho)=\log \operatorname{sig}((q-1) / \rho)+(q-1) \log \operatorname{sig}(-1 / \rho),
$$

where $\log \operatorname{sig}(x)=\left(1+e^{-x}\right)^{-1}$ is the sigmoid function. The characteristics of this function are illustrated in figure A1. When $\rho$ is close to zero, then productivity is zero until $q=1$, at which point it jumps to 1 . We call this a satisficing technology. This type of production would be a characteristic of jobs where the key feature is the presence of a worker correctly performing their job (given by $q=1$ ), but that higher levels of performance have little benefit for the firm. For example, correctly installing parts on a assembly line requires the worker to perform only up to the point that the part is correctly installed. Given that the pace of the line is fixed by management, there is no gain to extra effort. As $\rho$ increases in size, the production function become increasingly linear, with the case of $\rho=2$ also illustrated in the figure A1.

Consider now the profit maximizing choice of compensation system. Suppose that the firm can offer one of two types of contracts. The first, denoted $c^{f}=\left\{w^{*}, q^{*}\right\}$, pays the worker an hourly wage of $w^{*}$, as long as performance is $q^{*}$ or greater. It is assumed that there are sufficient penalties available, in the form of either turnover costs or forgone income,

\footnotetext{
${ }^{29} U_{w}>0, U_{e}<0, U_{w w} \leq 0, U_{e e}<0$, and $U_{w e} \leq 0$.
} 
to ensure that the worker performs adequately. Given that we have assumed all workers in $[\underline{\theta}, \bar{\theta}]$ are employed, then the firms solves:

$$
\begin{aligned}
\pi^{f}(\rho)= & \max _{w, q} g(q, \rho)-w, \text { subject to } \\
& U(w, q / \theta) \geq U(\theta), \forall \theta \in[\underline{\theta}, \bar{\theta}] .
\end{aligned}
$$

If the firm knew worker ability then the minimum effort required could be selected to reflect individual ability: $q^{*}(\theta)$. In practice there is a limit to the firm's knowledge of worker ability, an effect we have modelled by supposing all workers in the ability interval $[\underline{\theta}, \bar{\theta}]$ receive the same contract. In this case the firm can improve upon a fixed wage contract by offering a piece rate contract that allows to worker to choose effort that is commensurate with her skill level. Denote this contract by $c^{p}=\left\{T^{*}, p^{*}, q^{*}\right\}$, where the income of the worker is given by:

$$
W\left(c^{p}, q\right)=T^{*}+p^{*}\left(q-q^{*}\right),
$$

where the worker is required to perform at least at the level $q^{*}$. Notice that the piece rate contract includes a fixed wage contract as a special case, but is likely to be more expensive to implement due to the additional accounting requirements, given by $k>0$.

Given a piece rate contract $c^{p}$, each worker shall choose a level of output which maximizes her utility:

$$
Q\left(c^{p}, \theta\right)=\arg \max _{q \geq q^{*}} U\left(T^{*}+p^{*}\left(q-q^{*}\right), q / \theta\right) .
$$

It is straightforward to verify that when the constraint $q \geq q^{*}$ is not binding then $\partial Q / \partial p^{*}>0$, and $\partial Q / \partial \theta>0$ under the maintained assumptions on piece rates. Let the corresponding income for the worker be $W\left(c^{p}, \theta\right)=T^{*}+p^{*}\left(Q\left(c^{p}, \theta\right)-q^{*}\right)$. Given this function the firm chooses the contract to maximize profit:

A piece rate contract will be chosen whenever the benefits of superior matching outweigh the cost of implementation, or whenever $\pi^{p}(\rho)-k \geq$ $\pi^{f}(\rho)$. Let $\pi^{*}(\rho)$ be the gross profits when the firm can offer a type contingent contract then we have the following result summarizing the effect of $\rho$ upon the choice of compensation. ${ }^{30}$

$$
\begin{aligned}
\pi^{*}(\rho)= & \max _{q(\theta), w(\theta)} \int_{\underline{\theta}}^{\bar{\theta}}\{g(q(\theta), \rho)-w(\theta)\} f(\theta) d \theta \\
& \text { subject to } U(w(\theta), q(\theta) / \theta) \geq U(\theta), \forall \theta \in[\underline{\theta}, \bar{\theta}] .
\end{aligned}
$$


Proposition 1 When the job is characterized by a satisficing technology $(\rho=0)$, then $\pi^{p}(\rho)=\pi^{f}(\rho)=\pi^{*}(0)$, and the firm pays workers by the hour. For $\rho \in(0,1): \pi^{*}(\rho)>\pi^{p}(\rho)>\pi^{f}(\rho)$, and hence for $k$ sufficiently close to zero the firm uses a piece rate contract when $\rho>0$. Finally $\lim _{\rho \rightarrow \infty}\left\{\pi^{*}(\rho)-\pi^{p}(\rho)\right\}=0$, namely that a piece rate system is efficient when the technology is a linear function of effort.

\subsection{Contractible versus Non-contractible}

MacLeod (1996) shows that under the appropriate conditions, when employment is governed by a relational contract, a contract that is enforced by an implicit long term agreement rather than by the courts, then one may achieve the first best even when contracting is incomplete. ${ }^{31}$ Let us briefly sketch out the argument. Suppose that each period the employment relationship is characterized by the following sequence of moves:

1. The firm and worker agree upon compensation and expectations for performance (which may include the continuation of a previous agreement).

2. The state of the world $\omega_{t} \in \Omega$ is revealed.

3. The worker divides a time endowment of $Y$ among $k$ different tasks: $\mathbf{y}_{t} \in \Re^{K}$.

4. The principal pays the agent $W_{t}$.

5. Both principal and agent decide whether to continue the relationship or not.

The date is denoted by the subscript $t$, and $k$ is the number of possible tasks. Suppose that both the cost and benefit of different actions are unknown ex ante; for example a fireman may not know which house will catch fire; how difficult it will be to put out the fire; nor is he or she able to anticipate the set of actions that will need to be carried out upon entering the burning house. In this case the state space must incorporate both uncertain costs and benefits for each of the possible tasks:

$$
\Omega=\left\{\left\{\alpha^{1}, . ., \alpha^{n}\right\} \times\left\{\beta^{1}, . ., \beta^{m}\right\}\right\}^{k},
$$

\footnotetext{
${ }^{31}$ The notion of a relational contract is introduced by Macneil (1974). See also Williamson, Wachter, and Harris (1975), who introduce a general taxonomy of contract forms. The formal theory of relational contracting used here is based upon MacLeod and Malcomson (1989).
} 
where $\alpha_{k} \in\left\{\alpha^{1}, . ., \alpha^{n}\right\}$ denotes one of $n$ levels of productivity for task $k$, while $\beta_{k} \in\left\{\beta^{1}, . ., \beta^{m}\right\}$ represents one of the $m$ cost levels for task $k$. Notice that there are only a finite number of possible states (actually there are $n^{k} m^{k}$ states). The total benefit from an effort choice $\mathbf{y}_{t}$ is defined by $\alpha^{T} \mathbf{y}_{t}$ (boldface represents a vector), while the total cost to the worker of producing this effort is $C\left(\mathbf{y}_{t}, \beta\right)$, with the property that $C_{y_{i}}=\beta_{i}$.

With complete contracting, the worker and the firm would agree upon a state contingent contract $c(\omega)=(w(\omega), y(\omega)) \in X$ that defines the wage payment and the output expected from the worker for each state of nature. An efficient complete allocation of tasks, $\mathbf{y}^{*}(\omega)$ is the solution to the following program:

$$
\begin{aligned}
\mathbf{y}^{*}(\omega) & \in \arg \max _{\mathbf{y}^{\prime}} \alpha \mathbf{y}^{\prime}-C\left(\mathbf{y}^{\prime}, \beta\right), \text { subject to: } \\
\left|\mathbf{y}^{\prime}\right| & \equiv \sum_{i=1}^{k} y_{i}^{\prime}=Y .
\end{aligned}
$$

Letting $\bar{U}$ be the worker's default utility, then the wage is determined by:

$$
w^{*}(\omega)-C\left(\mathbf{y}^{*}(\omega), \beta\right)=\bar{U}, \forall \omega \in \Omega .
$$

Following Townsend (1979) and Dye (1985) suppose that there is a cost for including additional contract contingencies, given by $\gamma$ per contingency. Thus for this multi-tasking model the cost of implementing the complete contract procedure when all states occur with positive probability is $n^{k} m^{k} \gamma$.

It is important to observe is that the cost of the contract is an exponential function of the number of tasks. As the literature on computational complexity emphasizes (see Garey and Johnson (1979)) problems whose difficulty increases exponentially with their size are intractable. To see why this is the case suppose that $\gamma=1$ cent, and that the number of cost and performance levels are the same $(n=m)$. Table 11 presents the costs of the complete contract as a function of the number of tasks and effort levels. 


\begin{tabular}{l|llll}
\multirow{2}{*}{$\begin{array}{l}\text { Number of Cost and } \\
\text { Performance Levels }\end{array}$} & 2 & 5 & 10 & 15 \\
\hline \hline 2 & $\$ 0.16$ & $\$ 10$ & $\$ 10,000$ & $\$ 10$ million \\
3 & $\$ 0.81$ & $\$ 600$ & $\$ 35$ million & $\$ 2$ trillion \\
4 & $\$ 2.56$ & $\$ 10,000$ & $\$ 11$ billion & $\$ 11,000$ trillion \\
5 & $\$ 6.25$ & $\$ 100,000$ & $\$ 1000$ billion & $\$ 10$ million trillion \\
\hline \hline Cost of a contract clause: & 1 cent & &
\end{tabular}

Table 11: The Cost of a State Contingent Contract

As one can see, the use of a complete contract when there are more than say 10 tasks is impossible. Furthermore, given that these costs reflect the number of underlying states, dynamic programming is impossible because one could not compute the expected value of the relationship. In this table we have expressed the costs in terms of contracting costs, but observed that the large numbers also illustrate that complete planning is also impossible. Even thinking about and anticipating the correct response for every possible event is also impossible.

In contrast, observe that complete contracts are very inexpensive to implement when the number of dimensions of output are small. A natural criticism of the way we measure complexity is that one may argue that the mathematical formula for a given piece rate defining payment as a function of output is very simple, even though it describes payment for an infinite number of possible cases. The point here is that while technically we have modelled payoff depending upon underlying uncertainty in a smooth way, the intention is that each event is unique, and requires a separate analysis that may not apply to the other events, even if they are close by in the parameter space.

\section{Appendix 2}

In this Appendix we derive the estimators we use to correct for misclassification errors in the occupations. The first estimator is a direct adaptation in levels of the Krueger and Summers (1988) (K-S) first-difference estimator. We also use the K-S estimator directly when dealing with the PSID and NLSY data sets. The estimator in levels is first used to get consistent estimates of the group averages for the job characteristics. Then we use it to get consistent estimates of the occupation dummies estimated in the contract choice models.

Let 


$$
C=O^{*} \alpha+\epsilon
$$

where $C$ is an $\mathrm{N} \times 1$ vector of the dependent variable, $O^{*}$ is an $\mathrm{N} \mathrm{x} \mathrm{K}$ matrix of the true occupation dummies, $\alpha$ is a K-vector of coefficients and $\epsilon$ is an iid $\mathrm{N} \times 1$ vector of disturbances. Note the strong implicit assumption of orthogonality between the other explanatory variables $\mathrm{X}$ and the occupation dummies. As is the case for Krueger and Summers, this assumption is required for the technique derived below to work.

True occupational status is unobserved; instead we observe a noisy indicator $O$, which is assumed to be equal to the true occupational status plus a misclassification error:

$$
\begin{aligned}
O_{i k} & =O_{i k}^{*}+u_{i k} \\
i & =1, . . N \\
k & =1, . . K
\end{aligned}
$$

The occupation classification error term $u_{i k}$ is assumed to be iid and the possible values of $O_{i k}, O_{i k}^{*}$, and $u_{i k}$ are:

$$
O_{i k}, O_{i k}^{*} \in\{0,1\}, u_{i k} \in\{-1,0,1\} \text {. }
$$

We assume a simple measurement model in which the rate of misclassfication is considered constant for all occupations, the number of misclassifications depending on the proportion of the sample in each occupation category. ${ }^{32}$ Therefore:

$$
\begin{aligned}
r_{j k} & =\operatorname{Pr} \text { (worker in occupation } j \text { is falsely classified in occupation } k \text { ) } \\
& =r p_{k}
\end{aligned}
$$

where $p_{k}$ is the share of occupation $k$ in the population (for which we take the sample proportion to be an unbiased estimate). Thus, borrowing from Krueger and Summers' notation:

\footnotetext{
${ }^{32}$ Mellow and Sider (1983) report a mismatch rate of about $18 \%$ for one-digit occupations in the January 1977 CPS. Given that we are reluctant to use the employers' responses as the Gold Standard, we chose to use a rate of $9 \%$ for the misclassification rate. See Card (1996) on the likely extent of reporting error by employers on union status.
} 
$r_{k \bar{k}}=\operatorname{Pr}$ (worker in occupation $k$ is falsely classified in any other occupation)

$$
=\sum_{j \neq k}^{K} r p_{j}=r \sum_{j \neq k}^{K} p_{j}=r\left(1-p_{k}\right)
$$

$r_{\bar{k} k}=\operatorname{Pr}$ (worker is falsely classified in occupation $k$ )

$$
=r p_{k}
$$

The following table shows the conditional distribution of $u_{k}$ under the assumed misclassification process.

\begin{tabular}{ccc}
\multicolumn{3}{c}{$O_{k}^{*}$} \\
\hline$u_{k}$ & 1 & 0 \\
\hline-1 & 0 & $r p_{k}$ \\
\hline 0 & $1-r$ & $1-r p_{k}$ \\
\hline 1 & $r\left(1-p_{k}\right)$ & 0 \\
\hline Thus &
\end{tabular}

$$
E\left(u_{i k} \mid O_{i k}^{*}\right)=\left\{\begin{array}{c}
r\left(1-p_{k}\right), \text { if } O_{i k}^{*}=1 \\
-r p_{k}, \text { if } O_{i k}^{*}=0
\end{array}\right\}
$$

or, more compactly,

$$
E\left(u_{i k} \mid O_{i k}^{*}\right)=-r p_{k}+r\left(1-p_{k}\right) O_{i k}^{*}
$$

Using this result, we then have

$$
O_{i k}=O_{i k}^{*}(1-r)+r p_{k}+v_{i k}
$$

where $v_{i k}$ is a zero expectation error term uncorrelated with either $O^{*}$ or $v_{m l}$ for $m \neq i$ and $k \neq l$.

In matrix form, this can be written as

$$
O=O^{*}(I-R)-r P+V
$$

with

$$
\begin{aligned}
I & =K x K \text { identity matrix } \\
R & =K x K \text { diagonal matrix with typical element } R[k, k]=r \\
P & =N x K \text { matrix with typical element } P[n, m]=p_{m}
\end{aligned}
$$

Exploiting the fact that $P=N^{-1} \iota \iota^{\prime} O$ where $N$ is the sample size and $\iota \iota^{\prime}$ is an $N x N$ matrix of ones yields 


$$
\begin{aligned}
{\left[I-\left(r N^{-1}\right) \iota \iota^{\prime}\right] O } & =O^{*}(I-R)+V \\
\widetilde{O} & =O^{*}(I-R)+V
\end{aligned}
$$

where $\widetilde{O}$ is $O$ expressed in "quasi-differences" from means.

The same estimator used by Krueger and Summers can then be used to get a consistent estimate of $\alpha$, namely

$$
\alpha_{c}=\left(O^{* \prime} O^{*}\right)^{-1}(I-R)^{-1}\left(\widetilde{O}^{\prime} \widetilde{O}\right)^{-1} \widetilde{O}^{\prime} \alpha_{o l s}
$$

where $\alpha_{\text {ols }}=\left(\widetilde{O^{\prime}} \widetilde{O}\right)^{-1} \widetilde{O}^{\prime} C$. The proof of the consistency of $\alpha_{\text {ols }}$ is identical as the one in Krueger and Summers and thus is not shown here. In first difference, we simply use their estimator directly. ${ }^{33}$

An estimate of $\left(O^{* \prime} O^{*}\right)$ (the true occupation counts) is obtained in the following way: let $\widetilde{R}$ be the $\mathrm{K} \times \mathrm{K}$ matrix of misclassification probabilities with $r_{j k}$ as a typical element. Then

$$
\left(O^{* \prime} O^{*}\right)=\widetilde{R}^{-1}\left(O^{\prime} O\right)
$$

As noted above, the assumption of orthogonality between the occupation dummies and the other explanatory variables is quite strong and disputable. Thus, the estimation results should be seen with some caution. However, results (not reported here) from the two-step methodology excluding all regressor but the occupation dummies and without correcting for measurement error were qualitatively very similar to the results obtained with all the regressors included. Also, this estimator is very useful to get consistent estimates of the average job characteristics by occupation. The reason is that calculating these averages amounts to regressing individual-level responses on the full set of occupation dummies without any other regressor. Thus, we perform one such regression per job characteristic and apply the Krueger-Summers estimator adapted to levels derived above to get consistent estimates of the dummy coefficients i.e. the average of each job characteristic by occupation category.

\section{$9 \quad$ Appendix 3}

In this appendix, we outline the semi-parametric selection correction proposed by Dahl(1997).

\footnotetext{
${ }^{33}$ See also Fuller (1987), chapter 3, for another consistent estimator in levels when dummy variables are used as explanatory variables. A very useful survey on categorical data analysis is Kuha and Skinner(1995).
} 
Borrowing from Dahl's notation, let worker $i$ 's expected utility of working in occupation $\mathrm{k}$ when his previous occupation was $j$ be given by $V_{i j k}=V_{j k}+e_{i j k}$, where $V_{j k}$ is the population mean and $e_{i j k}$ is a personspecific error component. Then individuals move from occupation $j$ to occupation $k$ according to the following rule:

$$
\begin{aligned}
& M_{i j k}=1 \text { iff } V_{i j k}=\max \left(V_{i j 1}, . ., V_{i j K}\right) \\
& M_{i j k}=0 \text { otherwise }
\end{aligned}
$$

Letting $\epsilon_{i j k}$ be the error term in the "outcome equation" (the choice of a pay method), in general we expect that individuals in occupation $k$ may not be a random sample of the population and

$$
E\left(\epsilon_{i j k} \mid M_{i j k}=1\right)=E\left(\left(\epsilon_{i j k} \mid e_{i j m}-e_{i j k} \leq V_{j k}-V_{j m}, \neq \forall m\right) \neq 0\right.
$$

The size of the bias depends in turn on the covariance between the error term in the outcome equation and the error terms in the K "migration" equations. One way to address to selectivity issue would be to make distributional assumptions, as in the multinomial logit (MNL) for example. However, one feature of that model is to impose strong restrictions on the sign pattern of the bivariate covariances of the error terms in equation (32). Namely, the MNL requires the the K bivariate distributions to be monotonic and identical to each other. By non-parametrically modeling the distribution of the error terms in the selection equations, one can accommodate all possible sign patterns in the bivariate covariances.

If $c_{i j k}$ is the contract choice of worker $\mathrm{i}$ in occupation $\mathrm{k}$ who moved from occupation $j$, then

$$
c_{i j k} \text { observed iff } \max \mathbf{I}_{i j k} \leq 0
$$

where $\mathbf{I}_{i j k}=\left(V_{i j 1}-V_{i j k}, V_{i j 2}-V_{i j k}, . ., V_{i j K}-V_{i j k}\right)^{\prime}$. Let $f_{j k}\left(\epsilon_{i j k}, e_{i j 1}-\right.$ $\left.e_{i j k}, . ., e_{i j K}-e_{i j k}\right)$ be the joint distribution of the error terms in the outcome equation and the selection equations, with $F_{j k}\left(r, s_{1}, . ., s_{K}\right)$ the corresponding cumulative distribution and $f_{j k}^{e}\left(e_{i j 1}-e_{i j k}, . ., e_{i j K}-e_{i j k}\right)$ and $F_{j k}^{e}\left(s_{1}, . ., s_{K}\right)$, respectively the marginal density and marginal cumulative for occupation of origin $\mathrm{j}$ and present occupation k. Lee $(1982,1983)$ suggests that a way to simplify the problem is to focus on

$$
\begin{aligned}
H_{i j k}(r) & =\operatorname{Pr}\left(\max I_{i j k} \leq r\right) \\
& =\operatorname{Pr}\left(V_{j 1}-V_{j k}+e_{j 1}-e_{j k}<r, . ., V_{j K}-V_{j k}+e_{j K}-e_{j k}<r\right) \\
& =F_{j k}^{e}\left(V_{j 1}-V_{j k}+r, . ., V_{j K}-V_{j k}+r\right)
\end{aligned}
$$


$H_{i j k}$ is thus the probability of sample selection. Then, a new iid random variable can be constructed using the transformation

$$
u_{i j k}=G_{j k}^{u-1}\left(H_{i j k}\left(\max \mathbf{I}_{i j k}\right)\right)
$$

where $G_{j k}^{u-1}$ is any continuous univariate cumulative density function. Thus, the $K$ error terms from the selection equations have been reduced to a single error term. Given the selection rule in equation (34), the cdf $F_{j k}$ can be expressed as

$$
F_{j k}\left(r, s_{1}, . ., s_{K}\right)=G_{j k}\left(r, G_{j k}^{u-1}\left(F_{j k}^{e}\left(s_{1}, . ., s_{K}\right)\right)\right)
$$

One restriction imposed by Dahl is that the selection bias be characterized by the same distribution for everyone who lives in the same state, regardless of the state of origin. In short

$$
G_{j k}\left(r, s_{1}, . ., s_{K}\right)=G_{k}\left(r, s_{1}, . ., s_{K}\right), \forall j
$$

We also make the same assumption. Now, following Ahn and Powell (1993), let

$$
\begin{aligned}
p_{i j k} & =\operatorname{Pr} o b\left(\mathbf{I}_{i j k} \leq 0\right) \\
& =F_{j k}^{e}\left(V_{j 1}-V_{j k}, . ., V_{j K}-V_{j k}\right) \\
& =G_{j k}^{u}\left\{G_{j k}^{u-1}\left(F_{j k}^{e}\left(V_{j 1}-V_{j k}, . ., V_{j K}-V_{j k}\right)\right)\right\} \\
& =E\left(M_{i j k} \mid V_{j 1}-V_{j k}, . ., V_{j K}-V_{j k}\right)
\end{aligned}
$$

be the single index representing the conditional mean of the migration probability given the vector $\left(V_{j 1}-V_{j k}, . ., V_{j K}-V_{j k}\right)$. In general, single index models require that the conditional distribution of $\epsilon_{i j k}$ and $u_{i j k}$ given $\left(V_{j 1}-V_{j k}, . ., V_{j K}-V_{j k}\right)$ be the same as the conditional distribution of $\epsilon_{i j k}$ and $u_{i j k}$ given $p_{i j k}$. Then, one can write

$$
E\left(\epsilon_{i j k} \mid M_{i j k}=1\right)=\Phi_{k}\left(u_{i j k}\right)=\Phi\left(G_{j k}^{u-1}\left(p_{i j k}\right)\right)=\lambda_{k}\left(p_{i j k}\right)
$$

where $\lambda_{k}$ is an unknown function of the transition probability which we approximate by using a cubic function of $p_{i j k}$. As mentioned in the text, we estimate the selection probabilities by computing the "migration flows" between occupations. This non parametric way of estimating the selection probabilities avoids having to make assumptions regarding the distribution of the error terms in the selection equations. We compute the flows by grouping observations based on educational attainment 
and experience level. ${ }^{34}$ Dahl refers to the migration probability as the "propensity score". In the context of the present application, workers whose propensity scores are similar will have similar values for $V_{j k}$, the average gain in utility of moving from occupation $\mathrm{j}$ to occupation $\mathrm{k}$ and the selection correction term applicable to these workers will be the same. Therefore, identification of the occupation dummy coefficients is obtained through the restriction that the probability of being paid a certain way depends only on the present occupation while the "migration" decisions depend on both the present occupation and the previous occupation.

\footnotetext{
${ }^{34}$ Refining the grouping procedure by, say, gender and/or race did not make much difference.
} 


\section{References}

[1] Ahn, H. and J.L. Powell (1993). Semiparametric estimation of censored selection models with a nonparametric selection mechanism. Journal of Econometrics 58, 3-29.

[2] Antle, R. and A. Smith (1986). An empirical investigation of the relative performance evaluation of corporate executives. Journal of Accounting Research 24, 1-39.

[3] Becker, G.S. (1975).Human Capital: A Theoretical and Empirical Analysis, with Special Reference to Education (2 ed.). New York: Columbia University Press.

[4] Bishop, J. (1987). The recognition and reward of employee performance. Journal of Labor Economics 5 (4), S36-S56.

[5] Bishop, J.H. (1990).Job performance, turnover, and wage growth. Journal of Labor Economics 8 (3), 363-386.

[6] Borjas, G.J. and G.T. Sueyoshi (1994). A Two-Stage estimator for probit models. Journal of Econometrics, 165-182.

[7] Brown, C. (1990). Firms' choice of method of pay. In R.G. Ehrenberg (Ed.), Do Compensation Policies Matter?, pp. 165-182. Cornell University, Ithica, NY: ILR Press.

[8] Bull, C. (1987). The existence of self-enforcing implicit contracts. Quarterly Journal of Economics 102, 147-159.

[9] Card, D. (1996). The effect of unions on the structure of wages: A longitudinal analysis. Econometrica 64, 957-979.

[10] Carmichael, H.L. (1983, Spring). Firm-specific human capital and promotion ladders. Bell Journal of Economics 14 (1), 251-258.

[11] Chamberlain, G. (1980). Analysis of covariance with qualitative data. Review of Economic Studies 47, 225-238.

[12] Dahl, G.B. (1997). Mobility and the return to education: Testing a roy model with multiple markets. Industrial Relations Section Working Paper 381, Princeton University.

[13] Dye, R.A. (1985, February). Costly contract contingencies. International Economic Review 26 (1), 233-250. 
[14] Fuller, W. (1987). Measurement Error Models. New York: John Wiley \& Sons.

[15] Garey, M.R. and D.S. Johnson (1979). Computers and Intractability. New York, USA: W. H. Freeman and Co.

[16] Gibbons, R. (1987, October). Piece rate incentive schemes. Journal of Labor Economics 5, 413-29.

[17] Gibbons, R. and L.F. Katz (1991). Layoffs and lemons. Journal of Labor Economics $\mathbf{9}$ (4), 351-80.

[18] Gibbons, R. and K.J. Murphy (1992). Optimal incentive contracts in the presence of career concerns. Journal of Political Economy $100,30-52$.

[19] Grossman, S.J. and O.D. Hart (1986, August). The costs and benefits of ownership: A theory of vertical and lateral integration. Journal of Political Economy 94 (4), 691-719.

[20] Hausman, J. and D. McFadden (1984). Specification tests for the multinomial logit model. Econometrica 52, 1219-1240.

[21] Holmstrom, B. (1979). Moral hazard and observability. Bell Journal of Economics 10, 74-91.

[22] Holmström, B. (1982). Moral hazard in teams. Bell Journal of Economics 13, 324-40.

[23] Holmström, B. and P. Milgrom (1994, September). The firm as an incentive system. American Economic Review 84 (4), 972-991.

[24] Jensen, M. and K.J. Murphy (1990). Performance pay and top management incentives. Journal of Political Economy 98, 225-264.

[25] Kanemoto, Y. and W.B. Macleod (1992). The ratchet effect and the market for second hand workers. Journal of Labor Economics 10, $85-92$.

[26] Krueger, A.B. and L.H. Summers (1988, March). Efficiency wages and the inter-industry wage structure. Econometrica 56 (2), 259294.

[27] Kuha, J. and C. Skinner (1995). Categorical data analysis and misclassification. Technical report, Center for Survey Data Analysis, University of Southampton. 
[28] Lazear, E.P. (1986). Salaries and piece rates. Journal of Business $\mathbf{5 9}, 405-431$.

[29] Lazear, E.P. and S. Rosen (1981, October). Rank-order tournaments as optimal labor contracts. Journal of Political Economy 89, 841864 .

[30] Lee, L.F. (1982). Some Approaches to the Correction of Selectivity Bias. Review of Economic Studies XLIX, 355-372.

[31] Lee, L.F. (1983). Generalized Econometric Models for Selectivity. Econometrica 51, 507-512.

[32] MacLeod, W.B. (1996, June). Complexity, contract and the employment relationship. Technical Report 342, Boston College.

[33] MacLeod, W.B. and J.M. Malcomson (1989, March). Implicit contracts, incentive compatibility, and involuntary unemployment. Econometrica 57 (2), 447-480.

[34] MacLeod, W.B. and J.M. Malcomson (1997, October). Motivation and markets. Forthcoming in the American Economic Review.

[35] MacNeil, I.R. (1974). The many futures of contracts. Southern California Law Review 47 (688), 691-816.

[36] Maddala, G.S. (1983). Limited-Dependent and Qualitative Variables in Econometrics. Cambridge, U.K.: Cambridge University Press.

[37] McCall, B. (1990). Occupational matching: A test of sorts. Journal of Political Economy 98, 45-69.

[38] Mellow, W. and H. Sider (1983). Accuracy of response in labor market surveys: Evidence and implications. Journal of Labor Economics 1, 331-344.

[39] Moulton, B.R. (1986). Random group effects and the precision of regression estimates. Journal of Econometrics 32 (3), 385-397.

[40] Moulton, B.R. (1990). An illustration of the pitfalls in estimating the effecs of aggregate variables on micro units. Review of Economics and Statistics 72 (2), 334-338.

[41] Neal, D. (1996, March). The Complexity of Job Mobility among Young Men. Mimeo, University of Chicago. 
[42] Parent, D. (1997, April). Methods of pay and earnings: A longitudinal analysis. Technical Report 97s-14, CIRANO, Montreal, Canada.

[43] Pencavel, J.H. (1977). Work effort, on-the-job screening, and alternative methods of renumeration. In R. Ehrenberg (Ed.), Research in Labor Economics, Volume 1, pp. 225-58. Greenwich, Conn.: JAI Press.

[44] Prendergast, C. and R.H. Topel (1996). Favoritism in organizations. Journal of Political Economy 104 (5), 958-978.

[45] Rosenbaum, J.E. (1984). Career Mobility in a Corporate Hierarchy. New York, NY: Academic Press.

[46] Ross, S. (1973). Risk sharing and incentives in the principal and agent problem. American Economic Review 63, 134-39.

[47] Seiler, E. (1984, August). Piece rate vs. time rate: The effect of incentives on earnings. The Review of Economics and Statistics 66 (3), 363-376.

[48] Shapiro, C. and J.E. Stiglitz (1984, June). Equilibrium unemployment as a worker discipline device. American Economic Review $\mathbf{7 4}$ (3), 433-444.

[49] Shore-Sheppard, L. (1996, December). The precision of instrumental variables estimates with grouped data. Technical Report 374, Industrial Relations Section, Princeton University, Princeton, NJ.

[50] Simon, H.A. (1951, July). A formal theory of the employment relationship. Econometrica 19, 293-305.

[51] Small K.A. and C. Hsiao (1985). Multinomial Logit Specification Tests. International Economic Review 26, 619-627.

[52] Townsend, R. (1979). Optimal contracts and competitive markets with costly state verification. Journal of Economic Theory 22, 265293.

[53] Williamson, O.E. (1975). Markets and Hierarchies: Analysis and Antitruct Implications. New York: The Free Press.

[54] Williamson, O.E., M.L. Wachter, and J.E. Harris (1975, Spring). Understanding the employment relation: The analysis of idiosyncratic exchange. Bell Journal of Economics 6 (1), 250-278. 
Table 1

Mean Sample Statistics

\begin{tabular}{|c|c|c|c|c|}
\hline & $\begin{array}{c}\text { CPS } \\
(\text { Jan. 1977)* } \\
\end{array}$ & $\begin{array}{c}\text { QES } \\
(1973-77) \\
\end{array}$ & $\begin{array}{c}\text { PSID } \\
(1984-1991) \\
\end{array}$ & $\begin{array}{c}\text { NLSY } \\
(1988-1990) \\
\end{array}$ \\
\hline Schooling in Years & $\begin{array}{r}12,4 \\
(2.88)\end{array}$ & - & $\begin{array}{r}12,5 \\
(2.88)\end{array}$ & $\begin{array}{r}12,4 \\
(2.28)\end{array}$ \\
\hline$\%$ with High School Diploma & - & $\begin{array}{r}80,8 \\
(0.40)\end{array}$ & - & - \\
\hline Experience in Years & $\begin{array}{r}23,9 \\
(14.32)\end{array}$ & $\begin{array}{r}22,9 \\
(12.16)\end{array}$ & $\begin{array}{r}17,9 \\
(9,92)\end{array}$ & $\begin{array}{r}8,1 \\
(2.44)\end{array}$ \\
\hline Percentage Non-White & $\begin{array}{r}10,9 \\
(0.31)\end{array}$ & $\begin{array}{r}9,1 \\
(0.28)\end{array}$ & - & $\begin{array}{r}26,2 \\
(0.44)\end{array}$ \\
\hline Percentage Female & $\begin{array}{r}43,3 \\
(0.50)\end{array}$ & $\begin{array}{r}30,1 \\
(0.46)\end{array}$ & - & $\begin{array}{r}43,7 \\
(0.50)\end{array}$ \\
\hline Union Coverage & $\begin{array}{r}28,2 \\
(0.45)\end{array}$ & $\begin{array}{r}30,8 \\
(0.46)\end{array}$ & $\begin{array}{r}17,6 \\
(0.38)\end{array}$ & $\begin{array}{r}15,2 \\
(0.36)\end{array}$ \\
\hline Percentage Paid & & & & \\
\hline Hourly & $\begin{array}{r}58,6 \\
(0.50)\end{array}$ & $\begin{array}{r}40,9 \\
(0.49)\end{array}$ & $\begin{array}{r}48,6 \\
(0.50)\end{array}$ & $\begin{array}{r}45,9 \\
(0.50)\end{array}$ \\
\hline Salary & $\begin{array}{r}37,5 \\
(0.48)\end{array}$ & $\begin{array}{r}51,1 \\
(0.50)\end{array}$ & $\begin{array}{r}38,5 \\
(0.49)\end{array}$ & $\begin{array}{r}54,1 \\
(0.50)\end{array}$ \\
\hline Piece Rates & $\begin{array}{r}1,1 \\
(0.10)\end{array}$ & $\begin{array}{r}2,8 \\
(0.16)\end{array}$ & $\begin{array}{r}0,9 \\
(0.09)\end{array}$ & $\begin{array}{r}3,6 \\
(0.19)\end{array}$ \\
\hline Commissions & $\begin{array}{r}2,9 \\
(0.17)\end{array}$ & $\begin{array}{r}5,2 \\
(0.22)\end{array}$ & $\begin{array}{r}7,7 \\
(0.27)\end{array}$ & $\begin{array}{r}5,7 \\
(0.23)\end{array}$ \\
\hline Bonuses & $\begin{array}{r}8,4 \\
(0.2958)\end{array}$ & - & $\begin{array}{r}10,6 \\
(0.2902)\end{array}$ & $\begin{array}{r}14,1 \\
(0.35)\end{array}$ \\
\hline Average amount of bonuses $(\$$ & 1979)* & & & \\
\hline For Hourly Paid Workers & $\begin{array}{c}1079,09 \\
(1920.24)\end{array}$ & - & $\begin{array}{r}1203,35 \\
(2935.30)\end{array}$ & - \\
\hline For Salaried Workers & $\begin{array}{c}2313,05 \\
(5237.76)\end{array}$ & - & $\begin{array}{r}4403,86 \\
(8921.40)\end{array}$ & - \\
\hline Sample Size & 4905 & 724 & 10803 & 8165 \\
\hline
\end{tabular}

Notes. *Computed from workers' responses. 
Table 2

Average Characteristics By Pay Method-QES

\begin{tabular}{|c|c|c|c|c|c|c|}
\hline & Repetitiveness & $\begin{array}{l}\text { Variety } \\
\text { of Things }\end{array}$ & $\begin{array}{l}\text { Worker } \\
\text { Has Say }\end{array}$ & $\begin{array}{c}\text { Learn } \\
\text { New Things }\end{array}$ & Teamwork & $\begin{array}{c}\text { Set } \\
\text { Own Pace }\end{array}$ \\
\hline \multicolumn{7}{|c|}{ Panel A: Using Individual Data } \\
\hline Hourly & 0,6061 & 0,7913 & 0,5185 & 0,7643 & 0,6296 & 0,7306 \\
\hline Salary & 0,3925 & 0,9462 & 0,7554 & 0,9274 & 0,6344 & 0,8737 \\
\hline Piece Rate & 0,75 & 0,7 & 0,6 & 0,55 & 0,35 & 0,75 \\
\hline Commission & 0,579 & 0,8684 & 0,8421 & 0,8684 & 0,3158 & 0,8684 \\
\hline \multicolumn{7}{|c|}{ Panel B: Using Occupation } \\
\hline Hourly & 0,73449 & 0,75284 & 0,59588 & 0,74338 & 0,58772 & 0,74773 \\
\hline Salary & 0,63511 & 0,88287 & 0,77442 & 0,8808 & 0,55257 & 0,78395 \\
\hline Piece Rate & 0,72671 & 0,75325 & 0,66868 & 0,74468 & 0,51373 & 0,75409 \\
\hline Commission & 0,62151 & 0,84527 & 0,81603 & 0,88696 & 0,48162 & 0,79468 \\
\hline
\end{tabular}

Notes. In Panel A, averages are computed using each worker's reported value in 1977 for the different attributes. In Panel B, averages are computed using the occupation means calculated from the 1973-1977 observations. Cell entries represent the percentage of workers who consider their job as being characterized by the various features listed. 
Table 2A: Average Job Characteristics by Occupation, Quality of Employment Survey

\begin{tabular}{|c|c|c|c|c|c|c|}
\hline Occupation & Repetitiveness & $\begin{array}{l}\text { Variety } \\
\text { of Things }\end{array}$ & $\begin{array}{l}\text { Worker } \\
\text { Has Say }\end{array}$ & $\begin{array}{c}\text { Learn } \\
\text { New Things }\end{array}$ & Teamwork & $\begin{array}{c}\text { Set } \\
\text { Own Pace }\end{array}$ \\
\hline Prof., tech, except eng. techn. & $51,6 \%$ & $94,8 \%$ & $92,3 \%$ & $95,8 \%$ & $57,8 \%$ & $75,8 \%$ \\
\hline Engineering and science techn. & $58,4 \%$ & $80,7 \%$ & $52,9 \%$ & $94,6 \%$ & $82,5 \%$ & $88,4 \%$ \\
\hline Writers, artists, etc. & $28,0 \%$ & $96,1 \%$ & $96,1 \%$ & $96,1 \%$ & $58,4 \%$ & $58,4 \%$ \\
\hline Managers and admin. except farm & $60,5 \%$ & $97,7 \%$ & $93,2 \%$ & $94,5 \%$ & $41,3 \%$ & $84,4 \%$ \\
\hline Sales workers & $59,3 \%$ & $79,7 \%$ & $85,9 \%$ & $92,0 \%$ & $42,4 \%$ & $77,1 \%$ \\
\hline Clerical and unskilled $1 *$ & $74,9 \%$ & $75,5 \%$ & $65,0 \%$ & $80,8 \%$ & $67,1 \%$ & $86,9 \%$ \\
\hline Office machine operators & $83,9 \%$ & $75,8 \%$ & $48,7 \%$ & $86,6 \%$ & $62,6 \%$ & $62,6 \%$ \\
\hline Secretaries & $64,1 \%$ & $88,7 \%$ & $49,3 \%$ & $78,9 \%$ & $76,4 \%$ & $71,6 \%$ \\
\hline Clerical and unskilled $2 * *$ & $81,1 \%$ & $82,0 \%$ & $48,8 \%$ & $76,5 \%$ & $69,3 \%$ & $71,7 \%$ \\
\hline Craftsmen and kindred $1 * * *$ & $65,5 \%$ & $83,4 \%$ & $68,8 \%$ & $87,7 \%$ & $69,2 \%$ & $79,7 \%$ \\
\hline Mechanics and repairmen & $63,2 \%$ & $85,3 \%$ & $68,1 \%$ & $84,7 \%$ & $48,9 \%$ & $79,1 \%$ \\
\hline Operatives exc. prec. mach. \& text. & $77,4 \%$ & $52,7 \%$ & $45,3 \%$ & $56,0 \%$ & $66,0 \%$ & $54,5 \%$ \\
\hline Precision machine operatives & $84,1 \%$ & $53,7 \%$ & $51,9 \%$ & $48,3 \%$ & $56,4 \%$ & $62,6 \%$ \\
\hline Textile operators & $77,5 \%$ & $52,6 \%$ & $40,2 \%$ & $56,4 \%$ & $56,3 \%$ & $63,7 \%$ \\
\hline Transport equip. operatives & $86,8 \%$ & $62,0 \%$ & $48,5 \%$ & $60,9 \%$ & $52,8 \%$ & $81,9 \%$ \\
\hline Laborers, except farm & $97,6 \%$ & $85,4 \%$ & $46,1 \%$ & $56,9 \%$ & $76,4 \%$ & $90,7 \%$ \\
\hline Cleaning service workers & $79,6 \%$ & $88,1 \%$ & $76,7 \%$ & $73,9 \%$ & $28,7 \%$ & $78,9 \%$ \\
\hline Food service workers & $89,1 \%$ & $76,4 \%$ & $52,5 \%$ & $62,1 \%$ & $64,9 \%$ & $76,7 \%$ \\
\hline Health service workers & $76,6 \%$ & $67,7 \%$ & $41,2 \%$ & $91,3 \%$ & $54,6 \%$ & $54,6 \%$ \\
\hline Personal service workers & $68,8 \%$ & $80,1 \%$ & $66,5 \%$ & $83,4 \%$ & $44,3 \%$ & $76,7 \%$ \\
\hline
\end{tabular}


Table 2B

Average Job Characteristics by Occupation National Longitudinal Survey of Youth

\begin{tabular}{|c|c|c|c|c|c|}
\hline \multirow[b]{2}{*}{ Occupation } & \multicolumn{4}{|c|}{ Complete Variety } & \multirow{2}{*}{$\begin{array}{c}\text { Deal } \\
\text { With People }\end{array}$} \\
\hline & Autonomy & Task & of Tasks & Friendships & \\
\hline Prof., tech, except eng. techn. & $57,36 \%$ & $73,81 \%$ & $55,41 \%$ & $56,93 \%$ & $76,41 \%$ \\
\hline Engineering and science techn. & $61,59 \%$ & $78,81 \%$ & $56,95 \%$ & $58,28 \%$ & $65,56 \%$ \\
\hline Writers, artists, etc. & $67,68 \%$ & $76,77 \%$ & $54,55 \%$ & $65,66 \%$ & $73,74 \%$ \\
\hline Managers and admin. except farm & $61,13 \%$ & $77,48 \%$ & $64,61 \%$ & $56,84 \%$ & $90,08 \%$ \\
\hline Sales workers & $42,08 \%$ & $63,34 \%$ & $30,67 \%$ & $55,92 \%$ & $84,02 \%$ \\
\hline Clerical and unskilled $1^{*}$ & $32,77 \%$ & $65,88 \%$ & $30,67 \%$ & $49,87 \%$ & $72,79 \%$ \\
\hline Office machine operators & $39,75 \%$ & $62,46 \%$ & $38,80 \%$ & $48,90 \%$ & $59,62 \%$ \\
\hline Secretaries & $44,95 \%$ & $73,70 \%$ & $51,07 \%$ & $54,74 \%$ & $72,48 \%$ \\
\hline Clerical and unskilled $2 * *$ & $39,13 \%$ & $67,69 \%$ & $37,02 \%$ & $49,47 \%$ & $63,69 \%$ \\
\hline Craftsmen and kindred $1 * * *$ & $47,10 \%$ & $71,65 \%$ & $47,99 \%$ & $56,03 \%$ & $46,65 \%$ \\
\hline Mechanics and repairmen & $48,48 \%$ & $73,19 \%$ & $48,96 \%$ & $50,40 \%$ & $52,49 \%$ \\
\hline Operatives exc. prec. mach. \& text. & $32,64 \%$ & $57,46 \%$ & $33,01 \%$ & $48,29 \%$ & $44,99 \%$ \\
\hline Precision machine operatives & $28,92 \%$ & $48,59 \%$ & $26,51 \%$ & $50,20 \%$ & $33,33 \%$ \\
\hline Textile operators & $31,73 \%$ & $59,37 \%$ & $33,21 \%$ & $47,31 \%$ & $33,21 \%$ \\
\hline Transport equip. operatives & $40,25 \%$ & $65,50 \%$ & $33,25 \%$ & $48,50 \%$ & $62,25 \%$ \\
\hline Laborers, except farm & $33,04 \%$ & $62,73 \%$ & $30,89 \%$ & $48,44 \%$ & $45,49 \%$ \\
\hline Cleaning service workers & $34,93 \%$ & $64,95 \%$ & $27,34 \%$ & $40,07 \%$ & $33,65 \%$ \\
\hline Food service workers & $28,26 \%$ & $64,37 \%$ & $22,19 \%$ & $54,45 \%$ & $70,57 \%$ \\
\hline Health service workers & $37,99 \%$ & $68,16 \%$ & $39,94 \%$ & $62,01 \%$ & $82,12 \%$ \\
\hline Personal service workers & $47,96 \%$ & $66,19 \%$ & $33,09 \%$ & $58,03 \%$ & $74,10 \%$ \\
\hline
\end{tabular}

* From bank tellers to meter readers for utilities (Census 301 to 334)

**From shipping clerks to ticket agents and other misc clerks (Census 374 to 395)

***From auto access. installers to machinist apprentices (Census 401 to 462)

Cell entries represent the percentage of workers who consider their

job as having the various features listed. 
Table 3

Average Characteristics by Pay Method-NLSY

\begin{tabular}{lrrrrr}
\hline \hline & \multicolumn{1}{c}{ Complete } & \multicolumn{1}{c}{$\begin{array}{c}\text { Variety } \\
\text { of Tasks }\end{array}$} & Friendships & \multicolumn{1}{c}{$\begin{array}{c}\text { Deal } \\
\text { With People }\end{array}$} \\
Hourly & 0,40458 & 0,66452 & 0,38912 & 0,51679 & 0,58509 \\
Salary & 0,45426 & 0,69366 & 0,4393 & 0,5317 & 0,67194 \\
Piece Rate & 0,3574 & 0,60451 & 0,34556 & 0,49977 & 0,4624 \\
Commission & 0,46311 & 0,6818 & 0,40827 & 0,54133 & 0,72693 \\
Bonus & 0,46607 & 0,6936 & 0,45286 & 0,5351 & 0,69412 \\
\hline \hline
\end{tabular}

Notes. Cell entries represent the percentage of workers who consider their job as being characterized by the various features listed. 
Table 3A: Pay Method by Occupation, Quality of Employment Survey 1977

\begin{tabular}{lrrrr}
\hline \hline Occupation & Hourly & Salary & Piece Rate & Commission \\
\hline & & & & \\
Prof., tech, except eng. techn. & $14,15 \%$ & $83,02 \%$ & $0,94 \%$ & $1,89 \%$ \\
Engineering and science techn. & $28,57 \%$ & $71,43 \%$ & $0,00 \%$ & $0,00 \%$ \\
Writers, artists, etc. & $0,00 \%$ & $77,78 \%$ & $0,00 \%$ & $22,22 \%$ \\
Managers and admin. except farm & $8,33 \%$ & $81,82 \%$ & $2,27 \%$ & $7,58 \%$ \\
Sales workers & $27,27 \%$ & $9,09 \%$ & $4,55 \%$ & $59,09 \%$ \\
Clerical and unskilled 1* & $27,08 \%$ & $64,58 \%$ & $0,00 \%$ & $8,33 \%$ \\
Office machine operators & $30,77 \%$ & $69,23 \%$ & $0,00 \%$ & $0,00 \%$ \\
Secretaries & $17,65 \%$ & $82,35 \%$ & $0,00 \%$ & $0,00 \%$ \\
Clerical and unskilled 2** & $46,15 \%$ & $53,85 \%$ & $0,00 \%$ & $0,00 \%$ \\
Craftsmen and kindred 1*** & $59,02 \%$ & $34,43 \%$ & $4,92 \%$ & $1,64 \%$ \\
Mechanics and repairmen & $80,65 \%$ & $17,74 \%$ & $0,00 \%$ & $1,61 \%$ \\
Operatives exc. precis. machines \& text. & $74,19 \%$ & $22,58 \%$ & $3,23 \%$ & $0,00 \%$ \\
Precision machine operatives & $68,75 \%$ & $12,50 \%$ & $18,75 \%$ & $0,00 \%$ \\
Textile operators & $92,31 \%$ & $5,13 \%$ & $2,56 \%$ & $0,00 \%$ \\
Transport equip. operatives & $63,33 \%$ & $16,67 \%$ & $10,00 \%$ & $10,00 \%$ \\
Laborers, except farm & $85,00 \%$ & $15,00 \%$ & $0,00 \%$ & $0,00 \%$ \\
Cleaning service workers & $44,44 \%$ & $44,44 \%$ & $11,11 \%$ & $0,00 \%$ \\
Food service workers & $80,00 \%$ & $20,00 \%$ & $0,00 \%$ & $0,00 \%$ \\
Health service workers & $55,56 \%$ & $44,44 \%$ & $0,00 \%$ & $0,00 \%$ \\
Personal service workers & $23,08 \%$ & $61,54 \%$ & $7,69 \%$ & $7,69 \%$ \\
\hline \hline
\end{tabular}


Table 3B; Pay Method by Occupation, National Longitudinal Survey of Youth 1988-90

\begin{tabular}{|c|c|c|c|c|c|c|}
\hline Occupation & Hourly & Salary & Piece Rate & Commission & Bonus & Bonus 1 \\
\hline Prof., tech, except eng. techn. & $27,94 \%$ & $72,06 \%$ & $0,43 \%$ & $1,99 \%$ & $15,46 \%$ & $29,22 \%$ \\
\hline Engineering and science techn. & $42,37 \%$ & $57,63 \%$ & $0,00 \%$ & $5,09 \%$ & $9,32 \%$ & $27,97 \%$ \\
\hline Writers, artists, etc. & $21,84 \%$ & $78,16 \%$ & $2,30 \%$ & $9,20 \%$ & $17,24 \%$ & $32,18 \%$ \\
\hline Managers and admin. except farm & $19,98 \%$ & $80,02 \%$ & $0,68 \%$ & $9,84 \%$ & $28,46 \%$ & $47,37 \%$ \\
\hline Sales workers & $25,07 \%$ & $74,94 \%$ & $0,78 \%$ & $37,98 \%$ & $25,58 \%$ & $36,95 \%$ \\
\hline Clerical and unskilled $1 *$ & $43,18 \%$ & $56,83 \%$ & $1,34 \%$ & $3,12 \%$ & $13,21 \%$ & $29,53 \%$ \\
\hline Office machine operators & $43,88 \%$ & $56,12 \%$ & $0,84 \%$ & $1,27 \%$ & $13,50 \%$ & $28,27 \%$ \\
\hline Secretaries & $37,20 \%$ & $62,80 \%$ & $1,02 \%$ & $1,37 \%$ & $11,60 \%$ & $25,60 \%$ \\
\hline Clerical and unskilled $2 * *$ & $48,76 \%$ & $51,24 \%$ & $1,99 \%$ & $1,74 \%$ & $10,20 \%$ & $25,12 \%$ \\
\hline Craftsmen and kindred $1 * * *$ & $60,32 \%$ & $39,68 \%$ & $2,67 \%$ & $1,60 \%$ & $10,68 \%$ & $28,65 \%$ \\
\hline Mechanics and repairmen & $53,16 \%$ & $46,84 \%$ & $4,54 \%$ & $9,56 \%$ & $9,89 \%$ & $22,04 \%$ \\
\hline Operatives exc. precis. machines \& text. & $68,93 \%$ & $31,07 \%$ & $8,75 \%$ & $1,79 \%$ & $10,54 \%$ & $17,86 \%$ \\
\hline Precision machine operatives & $60,44 \%$ & $39,56 \%$ & $36,81 \%$ & $1,10 \%$ & $9,34 \%$ & $19,78 \%$ \\
\hline Textile operators & $66,67 \%$ & $33,33 \%$ & $9,76 \%$ & $0,71 \%$ & $11,43 \%$ & $21,43 \%$ \\
\hline Transport equip. operatives & $50,48 \%$ & $49,52 \%$ & $3,38 \%$ & $8,21 \%$ & $13,53 \%$ & $23,67 \%$ \\
\hline Laborers, except farm & $60,71 \%$ & $39,29 \%$ & $6,02 \%$ & $1,88 \%$ & $10,34 \%$ & $23,50 \%$ \\
\hline Cleaning service workers & $54,46 \%$ & $45,55 \%$ & $1,49 \%$ & $0,50 \%$ & $7,43 \%$ & $17,33 \%$ \\
\hline Food service workers & $52,46 \%$ & $47,55 \%$ & $0,52 \%$ & $1,29 \%$ & $7,49 \%$ & $18,86 \%$ \\
\hline Health service workers & $65,99 \%$ & $34,01 \%$ & $2,03 \%$ & $0,51 \%$ & $8,63 \%$ & $18,27 \%$ \\
\hline Personal service workers & $36,81 \%$ & $63,19 \%$ & $1,84 \%$ & $20,25 \%$ & $9,20 \%$ & $19,02 \%$ \\
\hline
\end{tabular}

* From bank tellers to meter readers for utilities (Census 301 to 334)

**From shipping clerks to ticket agents and other misc clerks (Census 374 to 395)

***From auto access. installers to machinist apprentices (Census 401 to 462)

Bonus1: includes promotions. 


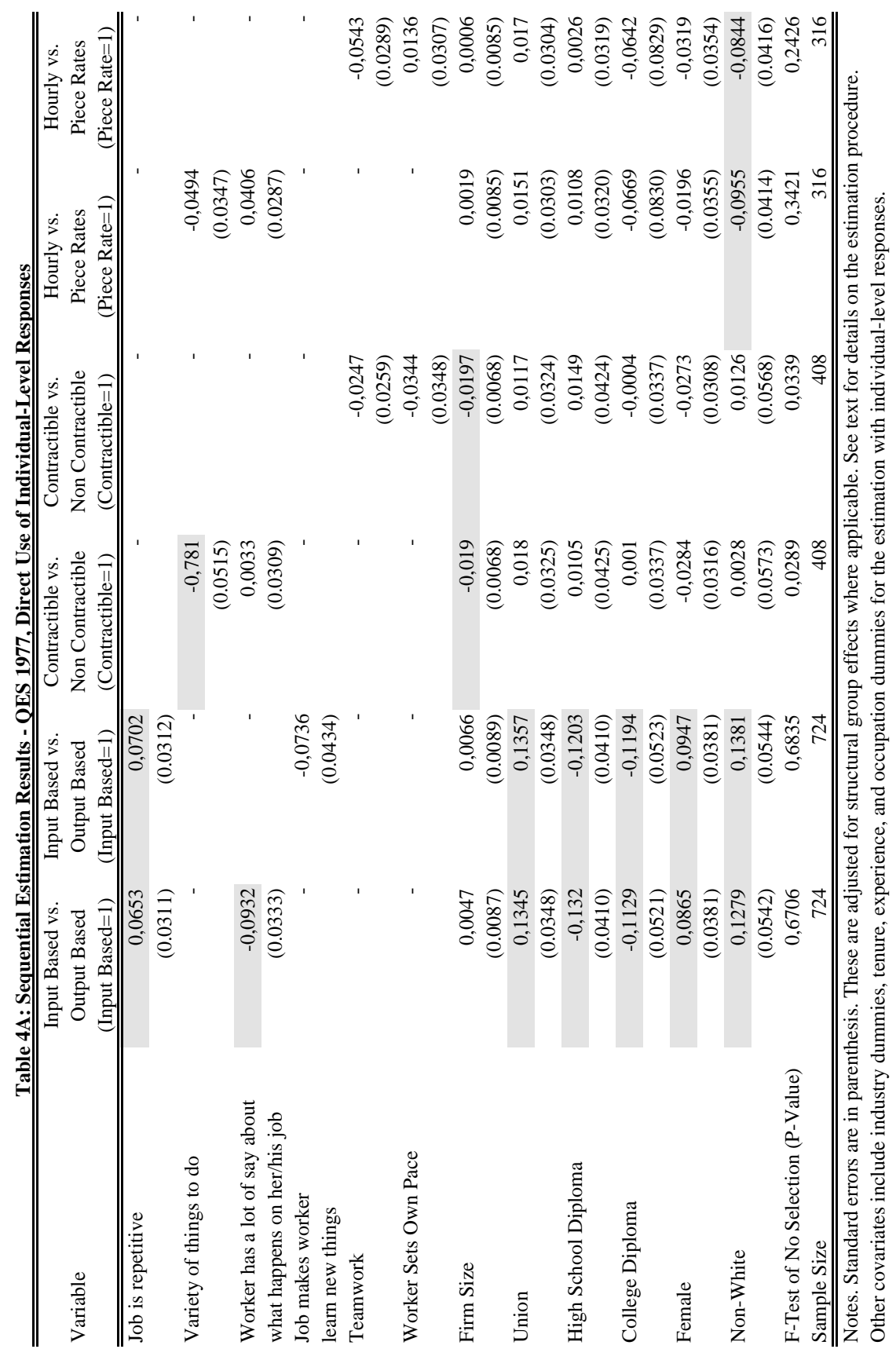




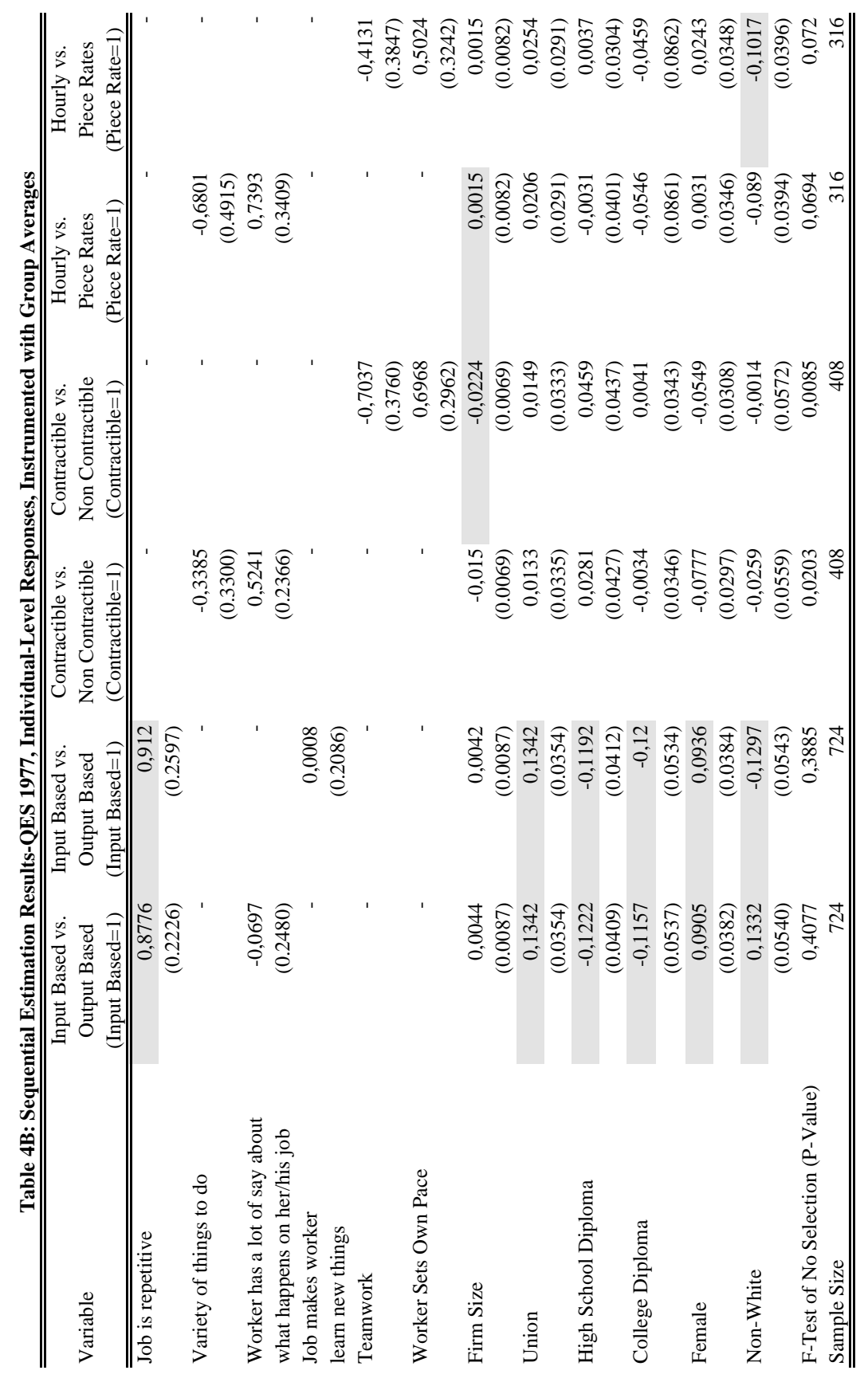




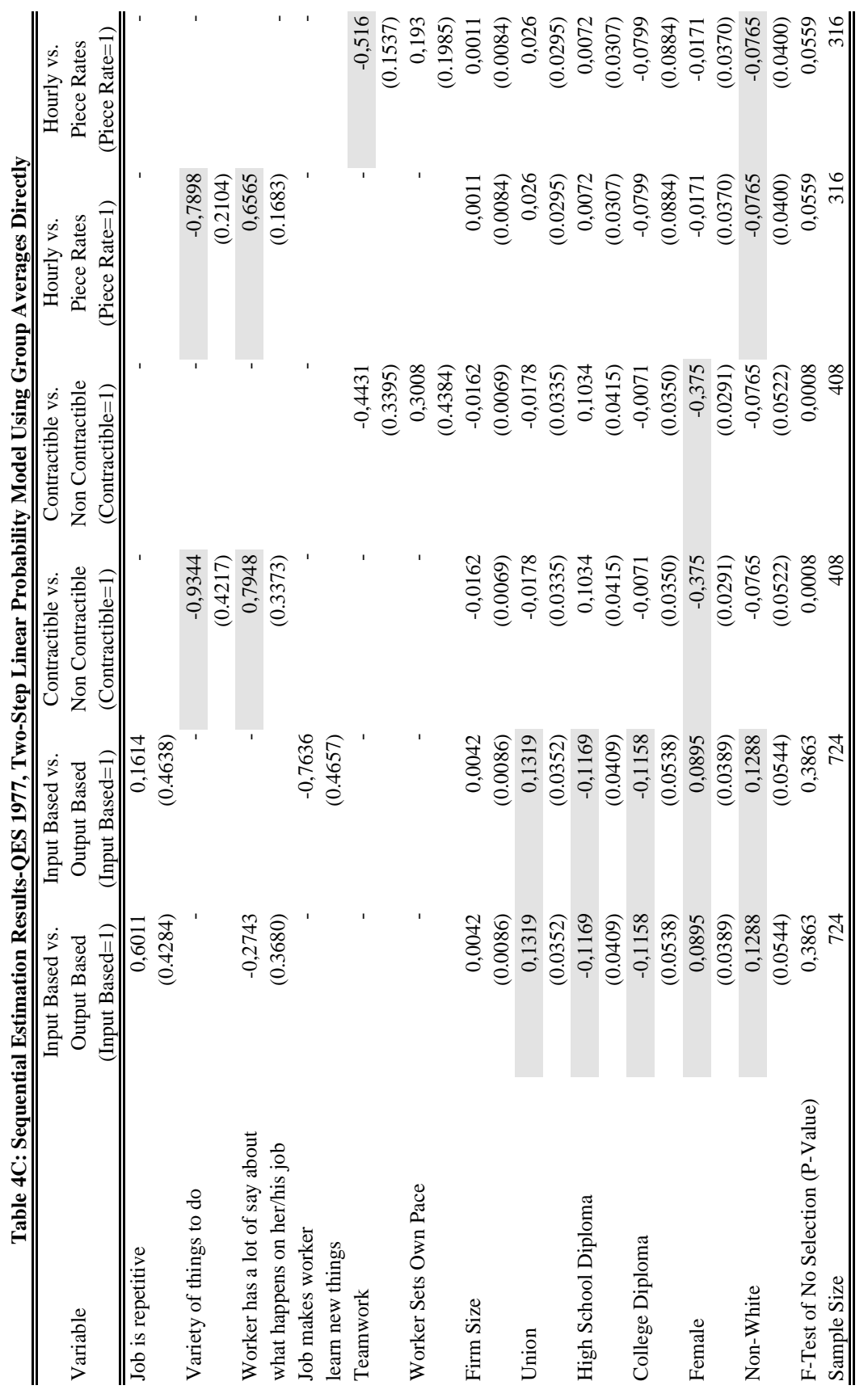




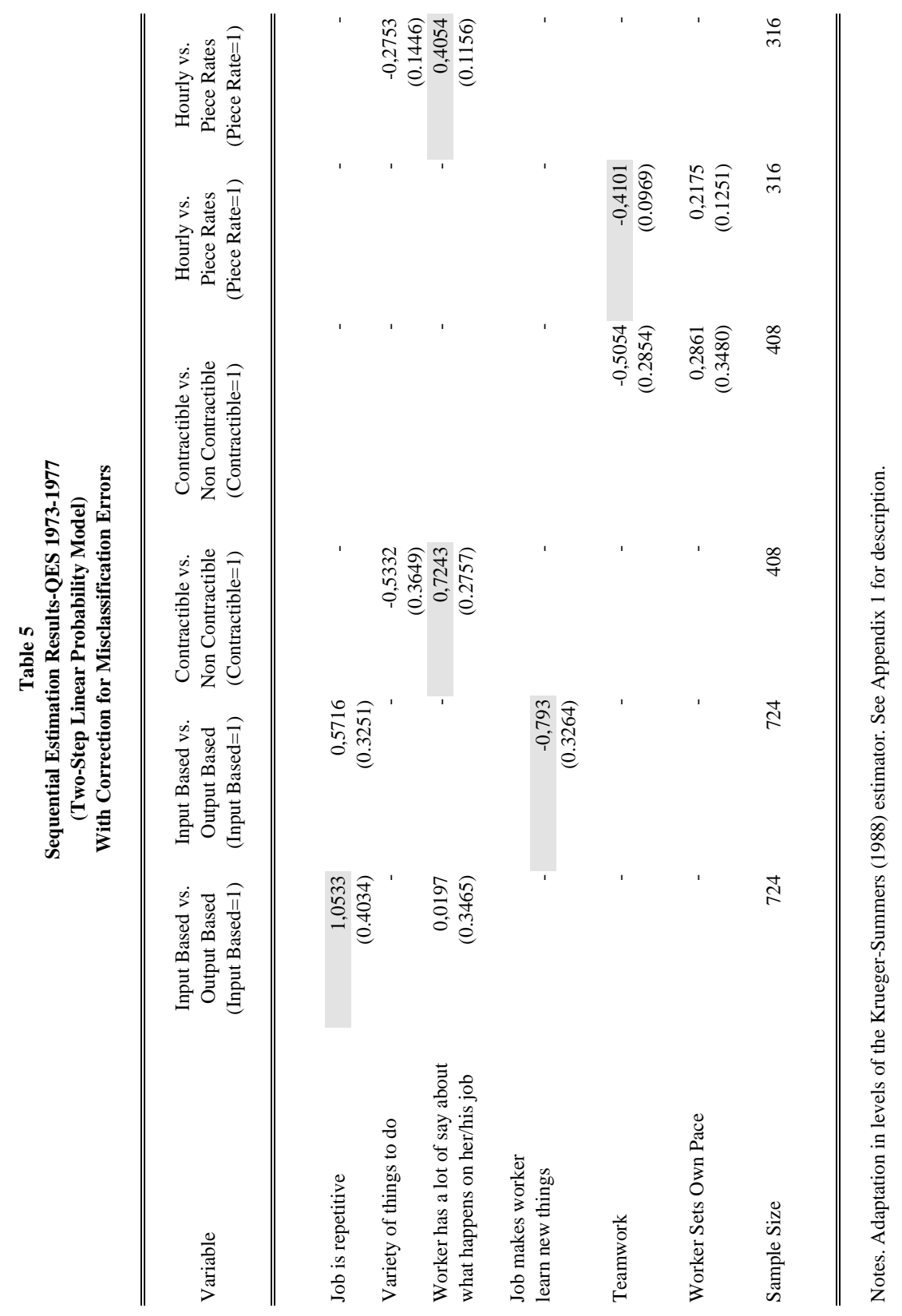


Table 6A: Sequential Estimation Results (Fixed-Effects)-NLSY 1988-1990, No Correction for Misclassification Errors.

\begin{tabular}{|c|c|c|c|c|}
\hline Variable & $\begin{array}{c}\text { Input Based vs. } \\
\text { Output Based } \\
\text { (Input Based=1) } \\
\end{array}$ & $\begin{array}{c}\text { Contractible vs. } \\
\text { Non-Contractible } \\
(\text { Contractible=1) } \\
\end{array}$ & $\begin{array}{c}\text { Bonus+Salary vs. } \\
\text { Salary+Termin. Contract } \\
\text { (Bonus-Salary=1) } \\
\end{array}$ & $\begin{array}{c}\text { Hourly vs. } \\
\text { Piece Rates } \\
\text { (Piece Rate }=1 \text { ) } \\
\end{array}$ \\
\hline \multirow[t]{2}{*}{ Autonomy } & $-1,38$ & 1,5634 & 0,982 & $-0,1331$ \\
\hline & $(0.3250)$ & $(0.4433)$ & $(0.9165)$ & $(0.5382)$ \\
\hline \multirow[t]{2}{*}{ Complete Task } & 0,8653 & $-0,7975$ & 0,3077 & $-1,4971$ \\
\hline & $(0.3835)$ & $(0.5231)$ & $(0.9044)$ & $(0.6352)$ \\
\hline \multirow[t]{2}{*}{ Variety } & 0,7249 & $-1,1221$ & $-1,1146$ & 0,9406 \\
\hline & $(0.2895)$ & $(0.3949)$ & $(0.7175)$ & $(0.4795)$ \\
\hline \multirow[t]{2}{*}{ Friendships } & 0.9155 & $-0,3344$ & $-0,3302$ & $-0,5213$ \\
\hline & $(0.3703)$ & $(0.5052)$ & (1.2908) & $(0.6105)$ \\
\hline \multirow[t]{2}{*}{ Deal with People } & $-0,7779$ & 0,2367 & 0,1426 & $-0,0435$ \\
\hline & $(0.1160)$ & $(0.1582)$ & $(0.2593)$ & $(0.1921)$ \\
\hline Unemployment Rate & 0,0149 & 0,0037 & $-0,0774$ & 0,0303 \\
\hline in Local Labor Market & $(0.0112)$ & $(0.0079)$ & $(0.0161)$ & $(0.0087)$ \\
\hline Unemployment Rate & - & - & $-0,0299$ & \\
\hline in Industry & & & $(0.0225)$ & \\
\hline \multirow[t]{2}{*}{ Schooling } & $-0,0193$ & 0,0014 & $-0,0104$ & $-0,0031$ \\
\hline & $(0.0150)$ & $(0.0163)$ & (0.0316) & $(0.0086)$ \\
\hline \multirow[t]{2}{*}{ Union } & 0,0034 & 0,0075 & -0.0807 & $-0,0042$ \\
\hline & (0.0188) & $(0.0166)$ & $(0.0336)$ & $(0.0122)$ \\
\hline \multicolumn{5}{|l|}{ F-Test of No Selection } \\
\hline (P-Value) & 0,0066 & 0,2599 & 0,7084 & 0,0878 \\
\hline Sample Size & 8165 & 4238 & 3832 & 3927 \\
\hline
\end{tabular}

Notes. Standard errors are in parenthesis. These are adjusted for structural group effects where applicable (except*). See text for details on the es estimation procedure. Other covariates include tenure, labor market experience, and dummies for region, industry, year, residence in smsa, and increase in responsibility. 
Table 6B

Sequential Estimation Results (Fixed-Effects)-NLSY 1988-1990 With Correction for Misclassification Errors.

\begin{tabular}{|c|c|c|c|}
\hline Variable & $\begin{array}{l}\text { Input Based vs. } \\
\text { Output Based } \\
\text { (Input Based=1) }\end{array}$ & $\begin{array}{l}\text { Contractible vs. } \\
\text { Non-Contractible } \\
(\text { Contractible }=1)\end{array}$ & $\begin{array}{c}\text { Hourly vs. } \\
\text { Piece Rates } \\
\text { (Piece Rate=1) }\end{array}$ \\
\hline \multirow[t]{2}{*}{ Autonomy } & $-1,2188$ & 2,2259 & $-0,1835$ \\
\hline & $(0.5707)$ & $(0.5464)$ & $(0.3536)$ \\
\hline \multirow[t]{2}{*}{ Complete Task } & -0.5984 & $-1,2647$ & $-1,4102$ \\
\hline & $(0.6225)$ & $(0.5960)$ & $(0.4173)$ \\
\hline \multirow[t]{2}{*}{ Variety } & 0.8995 & $-1,156$ & 0,6816 \\
\hline & $(0.4627)$ & $(0.4429)$ & $(0.3451)$ \\
\hline \multirow[t]{2}{*}{ Friendships } & 0.8156 & $-0,5861$ & $-0,0419$ \\
\hline & $(0.7096)$ & $(0.6794)$ & $(0.4029)$ \\
\hline \multirow[t]{2}{*}{ Deal with People } & -0.476 & 0,1735 & 0,0611 \\
\hline & $(0.3582)$ & $(0.3429)$ & $(0.1262)$ \\
\hline Sample Size & 8165 & 4238 & 3927 \\
\hline
\end{tabular}

Notes. Method used is Krueger-Summers (1988)'s estimator. See Appendix 1 for description. 
Table 7A: Sequential Estimation Results (Fixed-Effects)-PSID 1984-1991, No Correction for Misclassification Errors

\begin{tabular}{|c|c|c|c|c|c|c|c|}
\hline Variable & $\begin{array}{c}\text { Input Based vs. } \\
\text { Output Based } \\
\text { (Input Based=1) } \\
\end{array}$ & $\begin{array}{c}\text { Input Based vs. } \\
\text { Output Based } \\
\text { (Input Based=1) } \\
\end{array}$ & $\begin{array}{c}\text { Contractible vs. } \\
\text { Non-Contractible } \\
(\text { Contractible }=1) \\
\end{array}$ & $\begin{array}{c}\text { Contractible vs. } \\
\text { Non-Contractible } \\
(\text { Contractible=1) } \\
\end{array}$ & $\begin{array}{c}\text { Hourly vs. } \\
\text { Piece Rates } \\
\text { (Piece Rates }=1 \text { ) } \\
\end{array}$ & $\begin{array}{c}\text { Hourly vs. } \\
\text { Piece Rates } \\
\text { (Piece Rates }=1 \text { ) } \\
\end{array}$ & $\begin{array}{c}\text { Bonus+Salary vs. } \\
\text { Salary+Termin. Contract } \\
\text { (Bonus-Salary=1) } \\
\end{array}$ \\
\hline Job is repetitive & $\begin{array}{r}-0,1312 \\
(0.2205)\end{array}$ & $\begin{array}{r}0,0596 \\
(0.2567)\end{array}$ & - & - & - & - & - \\
\hline Variety of things to do & - & - & - & $\begin{array}{r}-1,0018 \\
(0.3997)\end{array}$ & - & $\begin{array}{r}-0,297 \\
(0.2671)\end{array}$ & - \\
\hline $\begin{array}{l}\text { Worker has a lot of say about } \\
\text { what happens on her/his job }\end{array}$ & $\begin{array}{r}-0,483 \\
(0.1881)\end{array}$ & $\begin{array}{r}-0,3081 \\
(0.2559)\end{array}$ & - & $\begin{array}{r}0,7232 \\
(0.2867)\end{array}$ & - & $\begin{array}{r}0,3499 \\
(0.2052)\end{array}$ & - \\
\hline Job makes worker learn new thing: & - & - & - & - & - & - & - \\
\hline Teamwork & - & - & $\begin{array}{r}-0,1789 \\
(0.1882)\end{array}$ & - & $\begin{array}{r}-0,2457 \\
(0.2671)\end{array}$ & - & - \\
\hline Worker Sets Own Pace & - & - & $\begin{array}{r}0,2326 \\
(0.2355)\end{array}$ & - & $\begin{array}{r}0,0989 \\
(0.2503)\end{array}$ & - & - \\
\hline $\begin{array}{l}\text { Unemployment Rate } \\
\text { in Local Labor Market }\end{array}$ & $\begin{array}{r}-0,0036 \\
(0.0017)\end{array}$ & $\begin{array}{r}-0,0036 \\
(0.0017)\end{array}$ & $\begin{array}{r}-0,0136 \\
(0.0246)\end{array}$ & $\begin{array}{r}-0,0136 \\
(0.0246)\end{array}$ & $\begin{array}{r}0,0009 \\
(0.0008)\end{array}$ & $\begin{array}{r}-0.0005 \\
(0.0046)\end{array}$ & $\begin{array}{r}-0,0067 \\
(0.0041)\end{array}$ \\
\hline $\begin{array}{l}\text { Unemployment Rate } \\
\text { in Industry }\end{array}$ & - & - & $\begin{array}{r}-0,0291 \\
(0.0134)\end{array}$ & - & - & - & - \\
\hline Union & $\begin{array}{r}0,0881 \\
(0.0115)\end{array}$ & $\begin{array}{r}0,0881 \\
(0.0115)\end{array}$ & $\begin{array}{r}-0,0136 \\
(0.0246)\end{array}$ & $\begin{array}{r}-0,0136 \\
(0.0246)\end{array}$ & $\begin{array}{r}-0,0005 \\
(0.0046)\end{array}$ & $\begin{array}{r}-0,0005 \\
(0.0046)\end{array}$ & $\begin{array}{r}0,0279 \\
(0.0518)\end{array}$ \\
\hline F-Test of No Selection (P-Value) & 0,3956 & 0,3956 & 0,5483 & 0,5483 & 0,0497 & 0,0497 & 0,0778 \\
\hline Sample Size & 10803 & 10803 & 5459 & 5459 & 5344 & 5344 & 4339 ** \\
\hline
\end{tabular}

Notes. Standard errors are in parenthesis. These are adjusted for structural group effects where applicable (except*). See text for details on the estimation procedure. Other covariants include tenure, labor market experience, schooling, and dummies for region, industry and year. *Observations for which the bonus measure is negative were deleted. 
Table 7B

Sequential Estimation Results (Fixed-Effects)-PSID 1984-1991.

With Correction for Misclassification Errors.

\begin{tabular}{|c|c|c|c|c|c|c|}
\hline Variable & $\begin{array}{l}\text { Input Based vs. } \\
\text { Output Based } \\
\text { (Input Based=1) }\end{array}$ & $\begin{array}{l}\text { Input Based vs. } \\
\text { Output Based } \\
\text { (Input Based=1) }\end{array}$ & $\begin{array}{l}\text { Contractible vs. } \\
\text { Non-Contractible } \\
(\text { Contractible }=1)\end{array}$ & $\begin{array}{l}\text { Contractible vs. } \\
\text { Non-Contractible } \\
(\text { Contractible }=1)\end{array}$ & $\begin{array}{c}\text { Hourly vs. } \\
\text { Piece Rates } \\
\text { (Piece Rates=1) }\end{array}$ & $\begin{array}{c}\text { Hourly vs. } \\
\text { Piece Rates } \\
\text { (Piece Rates=1) }\end{array}$ \\
\hline Job is repetitive & $\begin{array}{r}0,8467 \\
(0.5950)\end{array}$ & $\begin{array}{r}0,2036 \\
(0.4752)\end{array}$ & - & - & - & - \\
\hline Variety of things to do & - & - & - & $\begin{array}{r}-0,6451 \\
(0.4876)\end{array}$ & - & $\begin{array}{r}-0,3453 \\
(0.2692)\end{array}$ \\
\hline $\begin{array}{l}\text { Worker has a lot of say about } \\
\text { what happens on her/his job }\end{array}$ & $\begin{array}{r}-0,6409 \\
(0.5116)\end{array}$ & $\begin{array}{r}-1,6445 \\
(0.4785)\end{array}$ & - & $\begin{array}{r}0,5861 \\
(0.3688)\end{array}$ & - & $\begin{array}{r}0,405 \\
(0.2056)\end{array}$ \\
\hline $\begin{array}{l}\text { Job makes worker } \\
\text { learn new things }\end{array}$ & - & - & - & - & - & - \\
\hline Teamwork & - & - & $\begin{array}{r}-0,1379 \\
(0.3977)\end{array}$ & - & $\begin{array}{r}-0,274 \\
(0.2174)\end{array}$ & - \\
\hline Worker Sets Own Pace & - & - & $\begin{array}{r}-0,0742 \\
(0.4698)\end{array}$ & - & $\begin{array}{r}0,0825 \\
(0.2569)\end{array}$ & - \\
\hline Sample Size & 10803 & 10803 & 5459 & 5459 & 5344 & 5344 \\
\hline
\end{tabular}

Notes. Method used is Krueger-Summers (1988)'s estimator. See Appendix 1 for description. 
Table 8A

Sequential Estimation Results (Linear Probability Model)-CPS 1977. Workers' Responses No Correction for Misclasssification Errors.

\begin{tabular}{|c|c|c|c|c|c|c|c|}
\hline Variable & $\begin{array}{l}\text { Input Based vs. } \\
\text { Output Based } \\
\text { (Input Based=1) }\end{array}$ & $\begin{array}{l}\text { Input Based vs. } \\
\text { Output Based } \\
\text { (Input Based=1) }\end{array}$ & $\begin{array}{l}\text { Contractible vs. } \\
\text { Non-Contractible } \\
(\text { Contractible }=1)\end{array}$ & $\begin{array}{l}\text { Contractible vs. } \\
\text { Non-Contractible } \\
(\text { Contractible }=1)\end{array}$ & $\begin{array}{c}\text { Hourly vs. } \\
\text { Piece Rates } \\
\text { (Piece Rates=1) }\end{array}$ & $\begin{array}{c}\text { Hourly vs. } \\
\text { Piece Rates } \\
\text { (Piece Rates=1) }\end{array}$ & $\begin{array}{l}\text { Bonus+Salary vs. } \\
\text { Salary+Termin. } \\
\text { Contract } \\
\text { (Bonus-Salary=1) }\end{array}$ \\
\hline Job is repetitive & $\begin{array}{r}0,3859 \\
(0.3572)\end{array}$ & $\begin{array}{r}0,5177 \\
(0.2893)\end{array}$ & - & - & - & - & - \\
\hline Variety of things to do & - & - & - & $\begin{array}{r}-0,7905 \\
(0.4560)\end{array}$ & - & $\begin{array}{r}-0,3956 \\
(0.2109)\end{array}$ & - \\
\hline $\begin{array}{l}\text { Worker has a lot of say about } \\
\text { what happens on her/his job }\end{array}$ & $\begin{array}{r}-0,7361 \\
(0.3091)\end{array}$ & - & - & $\begin{array}{r}0,6634 \\
(0.3431)\end{array}$ & - & $\begin{array}{r}0,352 \\
(0.1593)\end{array}$ & - \\
\hline $\begin{array}{l}\text { Job makes worker } \\
\text { learn new things }\end{array}$ & - & $\begin{array}{r}-0,7827 \\
(0.2888)\end{array}$ & - & - & - & - & - \\
\hline Teamwork & - & - & $\begin{array}{r}-0,4646 \\
(0.3280)\end{array}$ & - & $\begin{array}{r}-0,2017 \\
(0.1854)\end{array}$ & - & - \\
\hline Worker Sets Own Pace & - & - & $\begin{array}{r}0,2376 \\
(0.3810)\end{array}$ & - & $\begin{array}{r}-0,0225 \\
(0.2153)\end{array}$ & - & - \\
\hline $\begin{array}{l}\text { Unemployment Rate } \\
\text { in Industry }\end{array}$ & - & - & & & - & - & $\begin{array}{r}-0,0046 \\
(0.0019)\end{array}$ \\
\hline Schooling & $\begin{array}{r}-0,0002 \\
(0.0019)\end{array}$ & $\begin{array}{r}-0,0002 \\
(0.0019)\end{array}$ & $\begin{array}{r}0,0021 \\
(0.0015)\end{array}$ & $\begin{array}{r}0,0021 \\
(0.0015)\end{array}$ & $\begin{array}{r}-0,0008 \\
(0.0011)\end{array}$ & $\begin{array}{r}-0,0008 \\
(0.0011)\end{array}$ & $\begin{array}{r}-0,0048 \\
(0.0089)\end{array}$ \\
\hline Union & $\begin{array}{r}0,1048 \\
(0.0151)\end{array}$ & $\begin{array}{r}0,1048 \\
(0.0151)\end{array}$ & $\begin{array}{r}-0,0112 \\
(0.0151)\end{array}$ & $\begin{array}{r}-0,0112 \\
(0.0151)\end{array}$ & $\begin{array}{r}-0,0152 \\
(0.0057)\end{array}$ & $\begin{array}{r}-0,0152 \\
(0.0057)\end{array}$ & $\begin{array}{r}0,0231 \\
(0.00181)\end{array}$ \\
\hline Non-White & $\begin{array}{r}0,0916 \\
(0.0179)\end{array}$ & $\begin{array}{r}0,0916 \\
(0.0179)\end{array}$ & $\begin{array}{r}-0,0071 \\
(0.0157)\end{array}$ & $\begin{array}{r}-0,0071 \\
(0.0157)\end{array}$ & $\begin{array}{r}0,0086 \\
(0.0071)\end{array}$ & $\begin{array}{r}0,0086 \\
(0.0071)\end{array}$ & $\begin{array}{l}-0,0205 \\
(0.0177)\end{array}$ \\
\hline Female & $\begin{array}{r}0,1556 \\
(0.0142)\end{array}$ & $\begin{array}{r}0,1556 \\
(0.0142)\end{array}$ & $\begin{array}{l}-0,0215 \\
(0.0116)\end{array}$ & $\begin{array}{r}-0,0215 \\
(0.0116)\end{array}$ & $\begin{array}{r}0,0146 \\
(0.0060)\end{array}$ & $\begin{array}{r}0,0146 \\
(0.0060)\end{array}$ & $\begin{array}{r}-0,0347 \\
(0.0170)\end{array}$ \\
\hline Sample Size & 4905 & 4905 & 1982 & 1982 & 2923 & 2923 & 1307 \\
\hline
\end{tabular}

Notes. Standard errors are in parenthesis. These are adjusted for structural group effects where applicable.

See text for details on the estimation procedure. Other covariates include potential experience, and dummies for industry. 
Table 8B

Sequential Estimation Results (Linear Probability Model)-CPS 1977. Workers' Responses With Correction for Misclasssification Errors.

\begin{tabular}{|c|c|c|c|c|c|c|}
\hline Variable & $\begin{array}{l}\text { Input Based vs. } \\
\text { Output Based } \\
\text { (Input Based=1) }\end{array}$ & $\begin{array}{l}\text { Input Based vs. } \\
\text { Output Based } \\
\text { (Input Based=1) }\end{array}$ & $\begin{array}{l}\text { Contractible vs. } \\
\text { Non-Contractible } \\
(\text { Contractible }=1)\end{array}$ & $\begin{array}{l}\text { Contractible vs. } \\
\text { Non-Contractible } \\
(\text { Contractible }=1)\end{array}$ & $\begin{array}{c}\text { Hourly vs. } \\
\text { Piece Rates } \\
\text { (Piece Rates=1) }\end{array}$ & $\begin{array}{c}\text { Hourly vs. } \\
\text { Piece Rates } \\
\text { (Piece Rates=1) }\end{array}$ \\
\hline Job is repetitive & $\begin{array}{r}0,5815 \\
(0.3113)\end{array}$ & $\begin{array}{r}0,2399 \\
(0.2805)\end{array}$ & - & - & - & - \\
\hline Variety of things to do & - & - & - & $\begin{array}{r}-0,3961 \\
(0.3187)\end{array}$ & - & $\begin{array}{r}-0,4048 \\
(0.1862)\end{array}$ \\
\hline $\begin{array}{l}\text { Worker has a lot of say about } \\
\text { what happens on her/his job }\end{array}$ & $\begin{array}{r}-0,4051 \\
(0.2845)\end{array}$ & - & - & $\begin{array}{r}0,4974 \\
(0.2407)\end{array}$ & - & $\begin{array}{r}0,3545 \\
(0.1407)\end{array}$ \\
\hline $\begin{array}{l}\text { Job makes worker } \\
\text { learn new things }\end{array}$ & - & $\begin{array}{r}-0,9718 \\
(0.2817)\end{array}$ & - & - & - & - \\
\hline Teamwork & - & - & $\begin{array}{r}-0,3818 \\
(0.2385)\end{array}$ & - & $\begin{array}{r}-0,2024 \\
(0.1507)\end{array}$ & - \\
\hline Worker Sets Own Pace & - & - & $\begin{array}{r}0,2729 \\
(0.2907)\end{array}$ & - & $\begin{array}{r}-0,0356 \\
(0.1837)\end{array}$ & - \\
\hline
\end{tabular}

Notes. Adaptation in levels of the Krueger-Summers (1988) estimator. See Appendix 1 for description. 


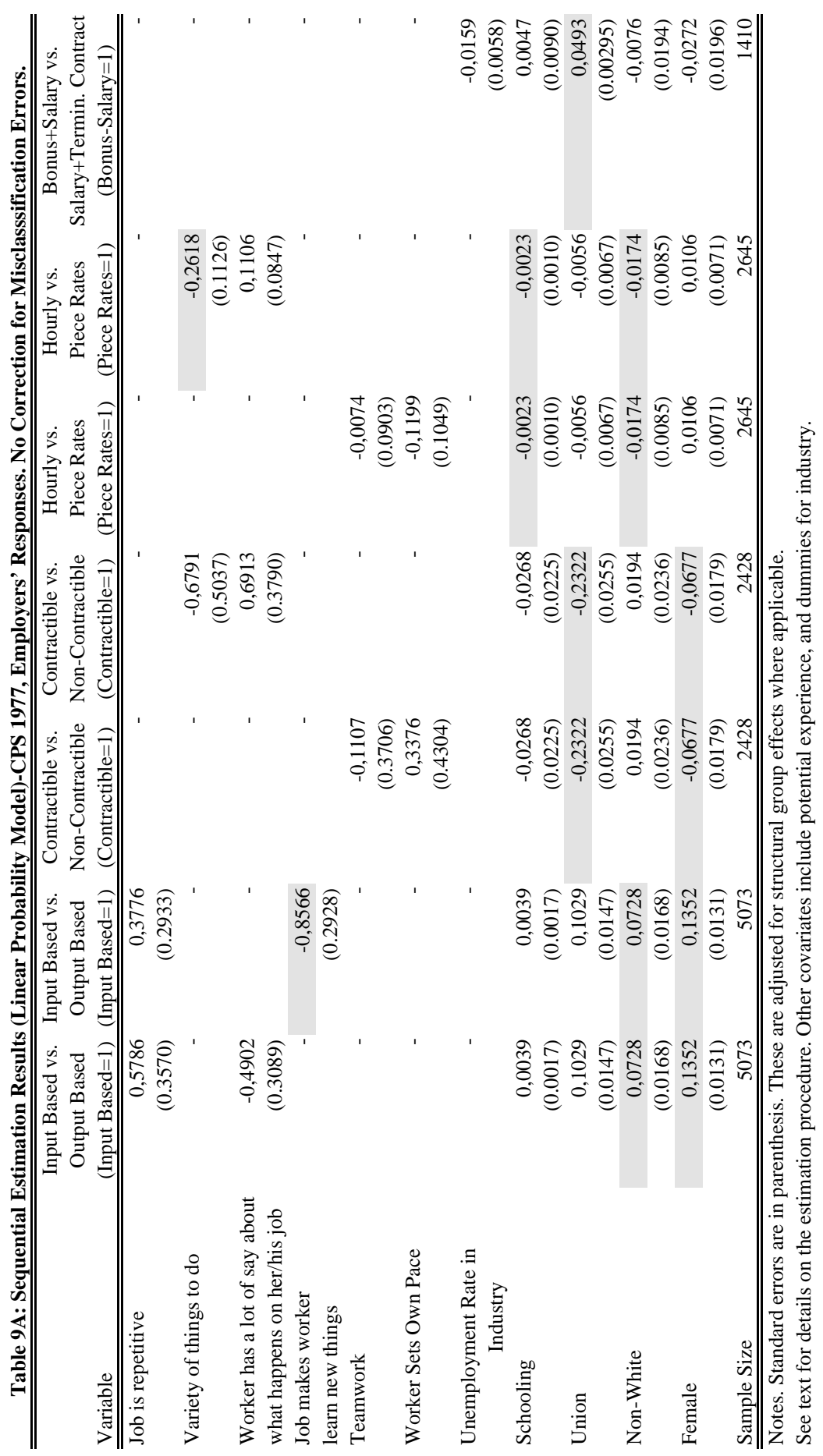


Table 9B

Sequential Estimation Results (Linear Probability Model)-CPS 1977, Employers' Responses With Correction for Misclasssification Errors.

\begin{tabular}{|c|c|c|c|c|c|c|}
\hline Variable & $\begin{array}{l}\text { Input Based vs. } \\
\text { Output Based } \\
\text { (Input Based=1) }\end{array}$ & $\begin{array}{l}\text { Input Based vs. } \\
\text { Output Based } \\
\text { (Input Based=1) }\end{array}$ & $\begin{array}{l}\text { Contractible vs. } \\
\text { Non-Contractible } \\
(\text { Contractible }=1)\end{array}$ & $\begin{array}{l}\text { Contractible vs. } \\
\text { Non-Contractible } \\
(\text { Contractible }=1)\end{array}$ & $\begin{array}{c}\text { Hourly vs. } \\
\text { Piece Rates } \\
\text { (Piece Rates=1) }\end{array}$ & $\begin{array}{c}\text { Hourly vs. } \\
\text { Piece Rates } \\
\text { (Piece Rates=1) }\end{array}$ \\
\hline Job is repetitive & $\begin{array}{r}0,7403 \\
(0.3433)\end{array}$ & $\begin{array}{r}0,3454 \\
(0.2808)\end{array}$ & - & - & - & - \\
\hline Variety of things to do & - & - & - & $\begin{array}{r}-0,2484 \\
(0.3668)\end{array}$ & - & $\begin{array}{r}-0,2695 \\
(0.0890)\end{array}$ \\
\hline $\begin{array}{l}\text { Worker has a lot of say about } \\
\text { what happens on her/his job }\end{array}$ & $\begin{array}{r}-0,1098 \\
(0.2949)\end{array}$ & - & - & $\begin{array}{r}0,3043 \\
(0.3771)\end{array}$ & - & $\begin{array}{r}0,0959 \\
(0.0672)\end{array}$ \\
\hline $\begin{array}{l}\text { Job makes worker } \\
\text { learn new things }\end{array}$ & - & $\begin{array}{r}-0,7416 \\
(0.2819)\end{array}$ & - & - & - & \\
\hline Teamwork & - & - & $\begin{array}{r}-0,1909 \\
(0.2771)\end{array}$ & - & $\begin{array}{r}-0,0213 \\
(0.0744)\end{array}$ & \\
\hline Worker Sets Own Pace & - & - & $\begin{array}{r}0,3508 \\
(0.2778)\end{array}$ & - & $\begin{array}{r}-0,0798 \\
(0.0907)\end{array}$ & \\
\hline
\end{tabular}

Notes. Adaptation in levels of the Krueger-Summers (1988) estimator. See Appendix 1 for description. 
Table 10

Test of Independence of Irrelevant Alternatives Assumption

Chi-Square Statistic

[Degrees of Freedom]

(P-Value)

\begin{tabular}{lllll}
\hline \hline & & & & \\
& QES & NLSY & PSID & CPS \\
\cline { 2 - 5 } & $14.23^{*}$ & $15.05^{* *}$ & $47.30^{*}$ & $10.36^{*}$ \\
Full Choice Set vs. & {$[16]$} & {$[28]$} & {$[33]$} & {$[12]$} \\
Excluding Input Based & $(0.5814)$ & $(0.9778)$ & $(0.0510)$ & $(0.5841)$ \\
Alternatives & & & & \\
& - & $8.68^{* *}$ & $7.26^{*}$ & $4.57^{* *}$ \\
Output Based Choice & & {$[28]$} & {$[33]$} & {$[12]$} \\
Set vs. Excluding Commissions & & $(0.9998)$ & $(0.9999)$ & $(0.9708)$ \\
& & & & \\
\hline \hline
\end{tabular}

Notes. *Hausman Test Statistic. **Small-Hsiao Test Statistic (used when Hausman statistic is negative). 
Figure 1: Average Characteristics by Pay Method - QES

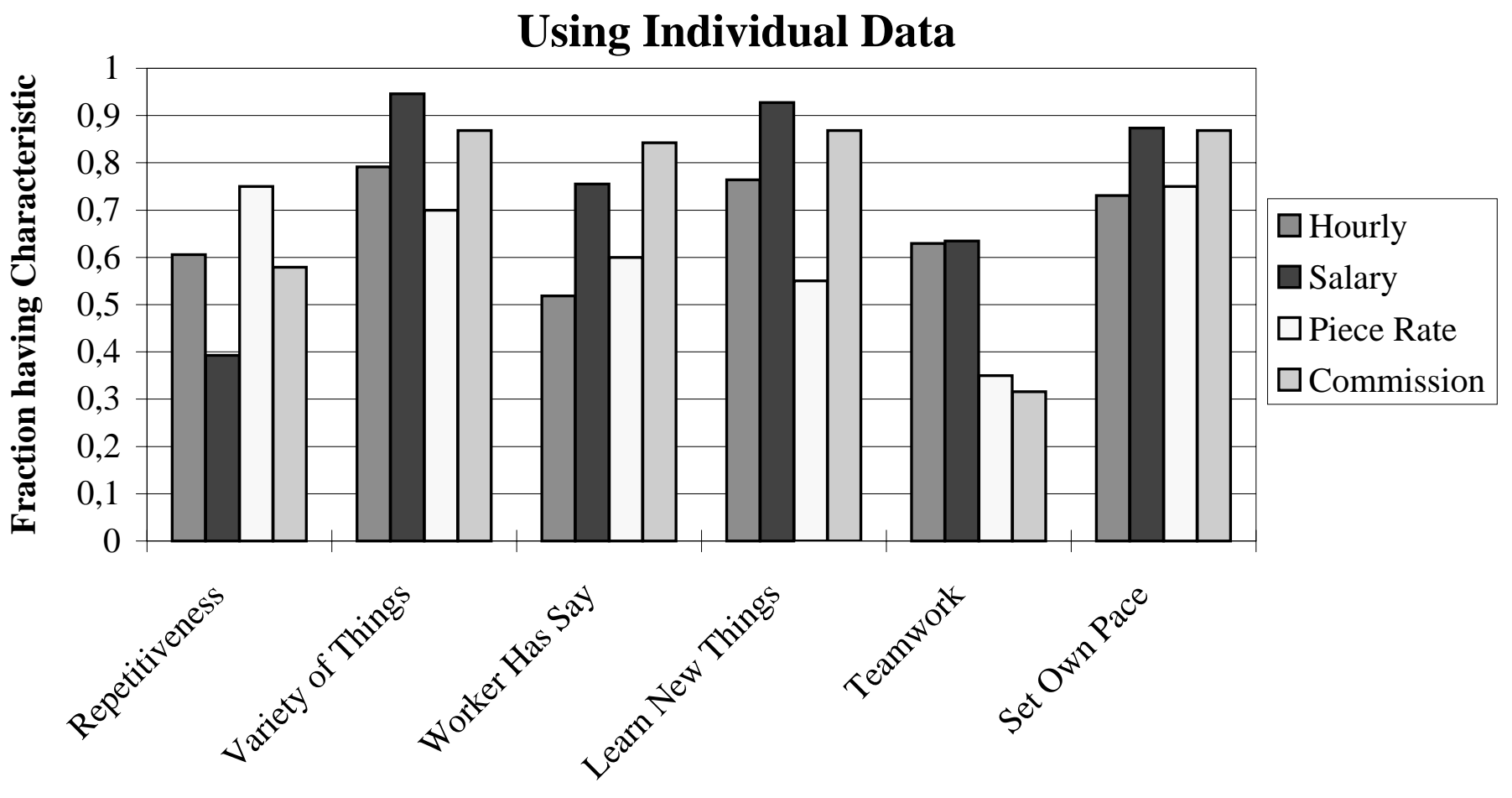


Figure 2: Average Characteristics by Pay Method - QES

Using Occupation Averages

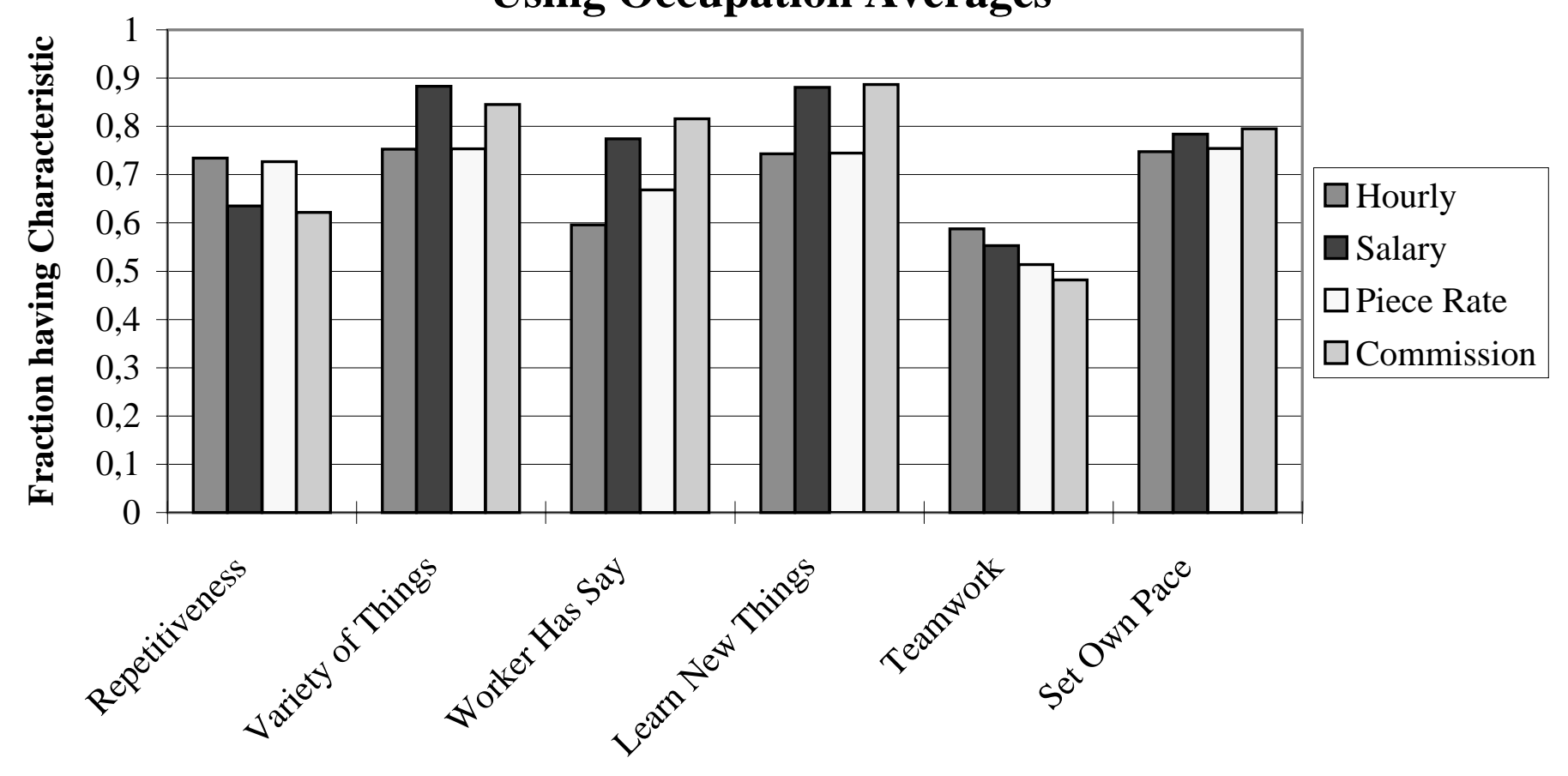


Figure 3: Average Characteristics by Pay Method - NLSY

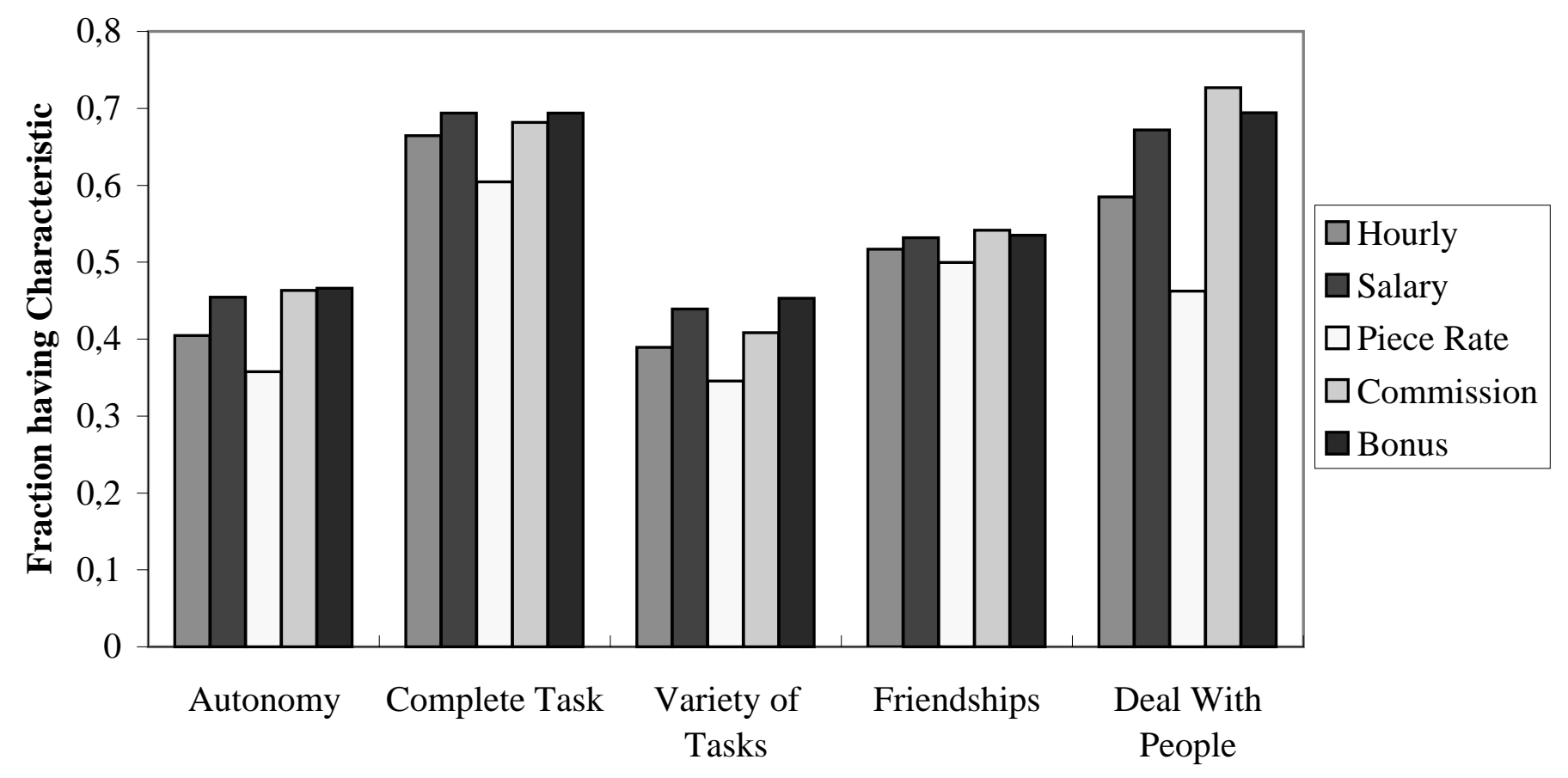


Figure 4: Distribution of Bonuses for Salaried Workers: PSID (1984-1991)

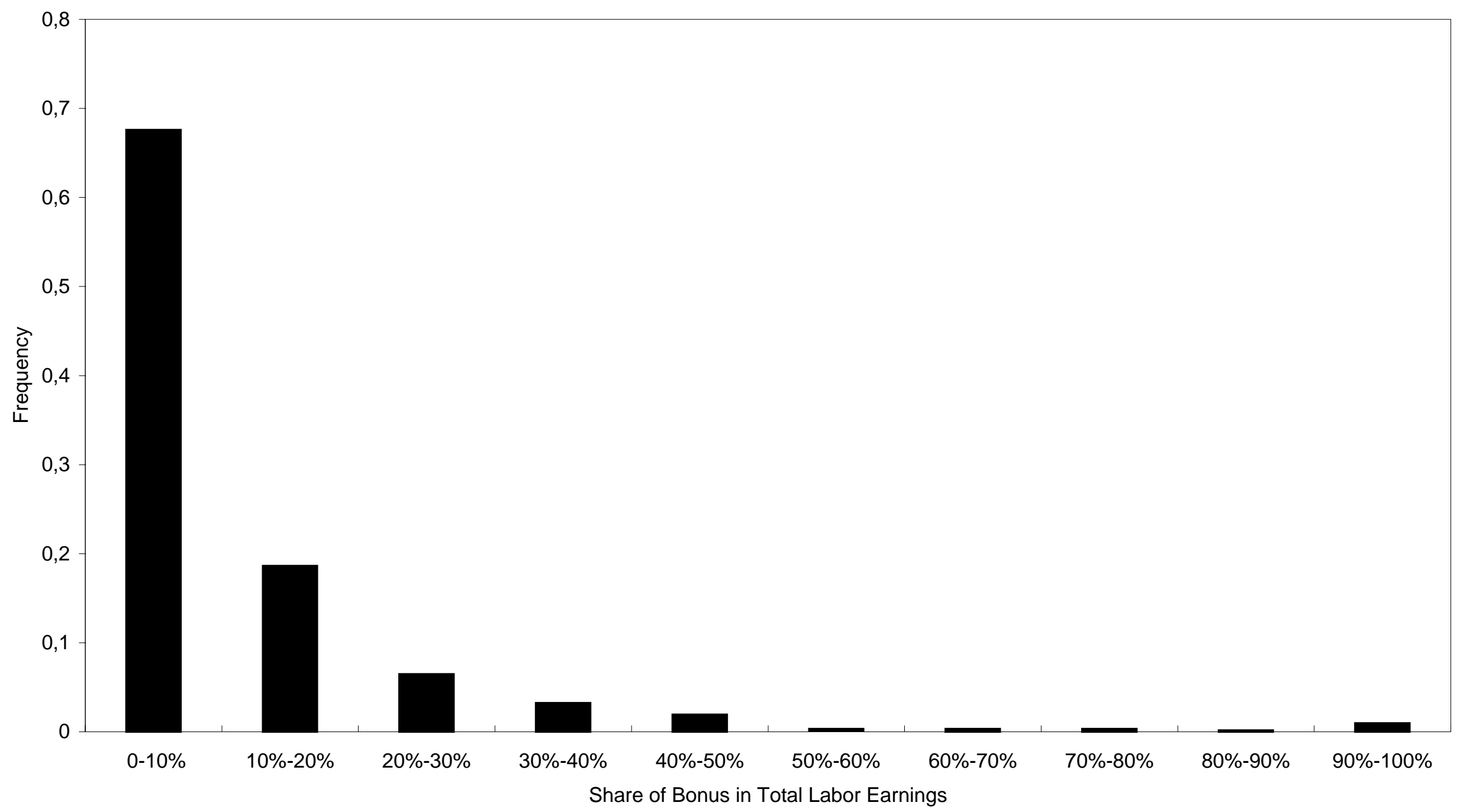


Figure 5: The Compensation Tree

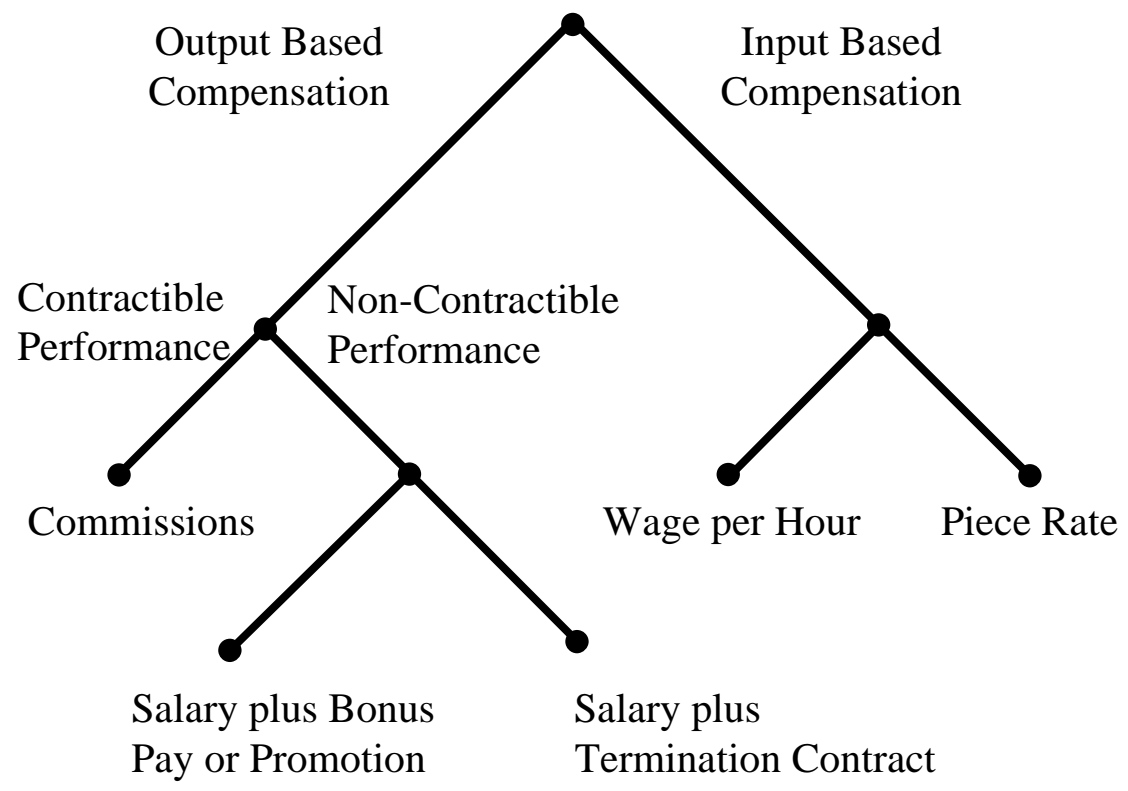




\section{Liste des publications au CIRANO *}

\section{Cahiers CIRANO / CIRANO Papers (ISSN 1198-8169)}

96c-1 Peut-on créer des emplois en réglementant le temps de travail ? / Robert Lacroix

95c-2 Anomalies de marché et sélection des titres au Canada / Richard Guay, Jean-François L'Her et Jean-Marc Suret

95c-1 La réglementation incitative / Marcel Boyer

94c-3 L'importance relative des gouvernements : causes, conséquences et organisations alternative / Claude Montmarquette

94c-2 Commercial Bankruptcy and Financial Reorganization in Canada / Jocelyn Martel

94c-1 Faire ou faire faire : La perspective de l'économie des organisations / Michel Patry

\section{Série Scientifique / Scientific Series (ISSN 1198-8177)}

98s-08 Job Characteristics and the Form of Compensation / W. Bentley MacLeod et Daniel Parent

98s-07 Technological Capability and Productivity Growth: An Industrialized / Industrializing Country Comparison / Pierre J. Tremblay

98s-06 L'évolution du taux d'activité des femmes au Canada, 1976-1994 : Une analyse de cohortes / Paul Beaudry et Thomas Lemieux

98s-05 Dix exemples de rentabilité financière liés à une saine gestion environnementale / Paul Lanoie et Georges A. Tanguay

98s-04 Effects of Workers' Compensation: A Survey / Bernard Fortin et Paul Lanoie

98s-03 Dépendance à l'égard de l'aide sociale et réforme de la sécurité du revenu / Bernard Fortin

98s-02 Risk Aversion, Intertemporal Substitution, and Option Pricing / René Garcia et Éric Renault

98s-01 Learning-by-Doing and Strategic Trade Policy / Hassan Benchekroun, Ngo Van Long et Huilan Tian

97s-42 Sector-Specific On-the-Job Training: Evidence from U.S. Data / Lars Vilhuber

97s-41 Competition and Access in Electricity Markets: ECPR, Global Price Cap, and Auctions / Marcel Boyer et Jacques Robert

97s-40 Strategic Adoption of a New Technology under Uncertain Implementation / Marcel Boyer et Séverine Clamens

97s-39 Seasonal Adjustment and Volatility Dynamics / Eric Ghysels, Clive W.J. Granger et Pierre L. Siklos

97s-38 How Do Young People Choose College Majors? / Claude Montmarquette, Kathy Cannings et Sophie Mahseredjian

97s-37 A General Equilibrium Analysis of the Evolution of the Canadian Service Productivity / Pierre Mohnen et Thijs ten Raa

97s-36 Moving towards the Virtual Economy: A Major Paradigm Shift / Louis A. Lefebvre et Élisabeth Lefebvre

* Vous pouvez consulter la liste complète des publications du CIRANO et les publications elles-mêmes sur notre site World Wide Web à l'adresse suivante :

http://www.cirano.umontreal.ca/publication/page1.html 